\title{
NSU
}

Florida

Nova Southeastern University

$\overline{\text { NOVA SOUTHEASTERN }}$

UNIVERSITY

NSUWorks

$1-1-2010$

\section{Identification of Effective Strategies to Promote Language in Deaf Children with Cochlear Implants}

Ivette Cruz

NovaSoutheastern University, icejas@med.miami.edu

This document is a product of extensive research conducted at the Nova Southeastern University College of Psychology. For more information on research and degree programs at the NSU College of Psychology, please click here.

Follow this and additional works at: https://nsuworks.nova.edu/cps_stuetd

Part of the Psychology Commons

\section{Share Feedback About This Item}

\section{NSUWorks Citation}

Cruz, I. (2010). Identification of Effective Strategies to Promote Language in Deaf Children with Cochlear Implants. .

Available at: https://nsuworks.nova.edu/cps_stuetd/23

This Dissertation is brought to you by the College of Psychology at NSUWorks. It has been accepted for inclusion in College of Psychology Theses and Dissertations by an authorized administrator of NSUWorks. For more information, please contact nsuworks@nova.edu. 


\title{
IDENTIFICATION OF EFFECTIVE STRATEGIES TO PROMOTE LANGUAGE IN DEAF CHILDREN WITH COCHLEAR IMPLANTS
}

\author{
by \\ Ivette Cruz \\ A Dissertation Presented to the School of Psychology \\ of Nova Southeastern University \\ in Partial Fulfillment of the Requirements \\ for the Degree of Doctor of Philosophy
}

NOVA SOUTHEASTERN UNIVERSITY

2010 


\section{DISSERTATION APPROVAL SHEET}

This dissertation was submitted by Ivette Cruz under direction of the Chairperson of the dissertation committee listed below. It was submitted to the School of Psychology and approved in partial fulfillment of the requirements for the degree of Doctor of Philosophy in Clinical Psychology at Nova Southeastern University.

Approved:

Date of Defense

Jan Faust, Ph.D., Chairperson

Craig Marker, Ph.D.

Barry Nierenberg, Ph.D.

Alexandra L. Quittner, Ph.D.

$\overline{\text { Date of Final Approval }}$

Jan Faust, Ph.D., Chairperson 


\section{ACKNOWLEDGMENTS}

I would like to thank the parents and children who participated in this study. I would also like to thank all the undergraduate students and research assistants at the University of Miami who helped me code the parent-child interactions. In addition, I would also like to thank my dissertation committee for their support and feedback throughout the dissertation process. The research was supported by the National Institute of Deafness and other Communication Disorders R01DC004797 (JK Niparko, PI Principal Investigator) and by a NIH R01 Minority Supplement Award (PHS R01 \#DC04797). 


\section{TABLE OF CONTENTS}

LIST OF TABLES............................................................................... vi

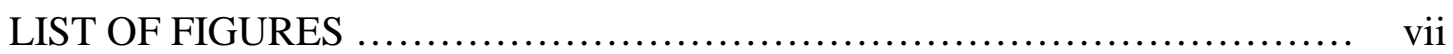

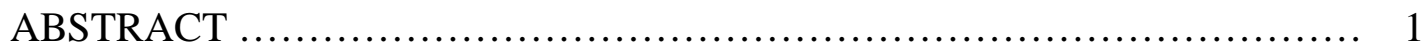

CHAPTER I: STATEMENT OF THE PROBLEM …....................... 3

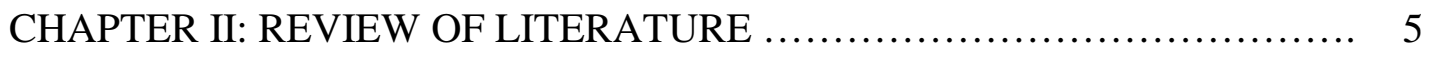

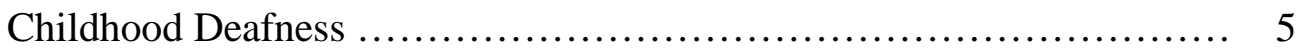

Cochlear Implants ................................................ 7

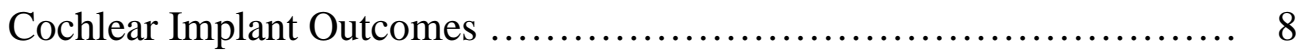

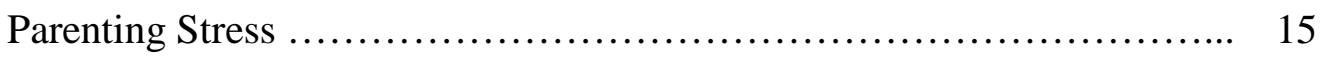

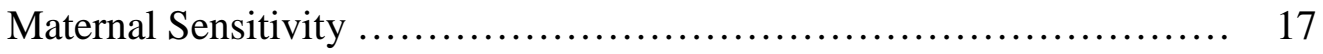

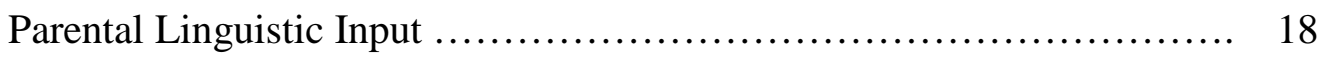

Facilitative Language Techniques ............................ $\quad 20$

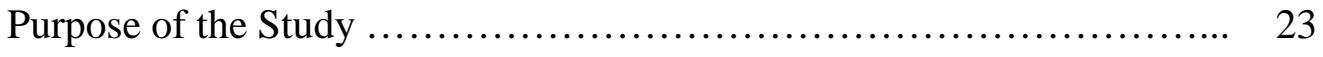

Study Aims \& Hypotheses ....................................... 23

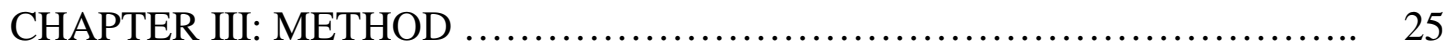

Participants ...................................................... 25

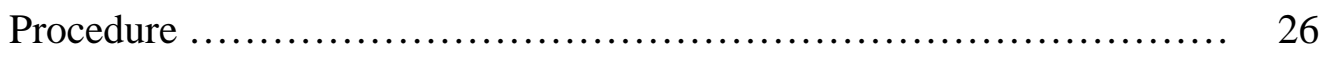

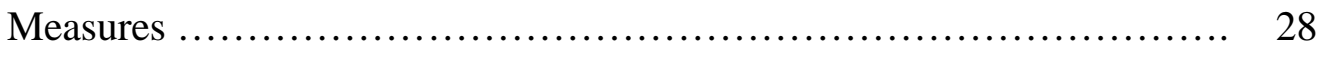

CHAPTER IV: RESULTS .............................................. 33

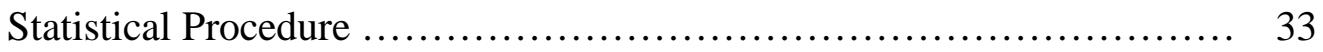

Descriptive Statistics ............................................. 34

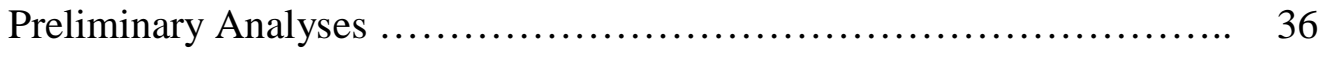


Task Differences .................................................. 36

Univariate Latent Growth Curve Modeling .......................... 43

Dual Latent Growth Curve Modeling ............................... 48

Bivariate Latent Difference Score Modeling ........................ 54

CHAPTER V: DISCUSSION ............................................ 61

The Hypotheses \& Summary of the Results ........................... 61

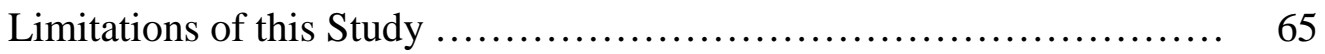

Clinical Implications and Future Directions ......................... 65

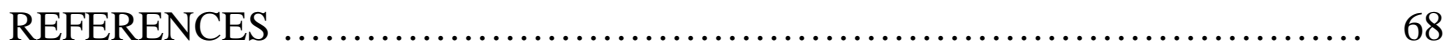

APPENDICES [.......................................................... 81

A. Parenting Strategies Communication Coding System ................ 81 


\section{LIST OF TABLES}

Table

Page

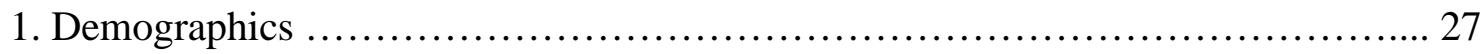

2. Description and Examples of Lower-Level Parental Facilitative Language .......... 31 Techniques

3. Description and Examples of Higher-Level Parental Facilitative Language 32 Techniques

4. Means and Standard Deviations for Facilitative Language Techniques and 35 Language Measures

5. Facilitative Language Techniques and Parent Utterances by Task ............... 38 


\section{LIST OF FIGURES}

Figure

Page

1. Description of How a Cochlear Implant Functions ............................. 9

2. Repeated Measures - Analysis of Variance: Parent Utterances by Task ............ 39

3. Repeated Measures - Analysis of Variance: Mean Length of Utterance by Task ... 40

4. Repeated Measures - Analysis of Variance: Lower-Level Strategies by Task ....... 41

5. Repeated Measures - Analysis of Variance: Higher-Level Strategies by Task ..... 42

6. Univariate Latent Growth Curve Model: Lower-Level Strategies .................. 44

7. Univariate Latent Growth Curve Model: Higher-Level Strategies ................. 45

8. Univariate Latent Growth Curve Model: Expressive Language .................. 46

9. Univariate Latent Growth Curve Model: Receptive Language ................... 47

10. Dual Latent Growth Curve Model: Lower-Level Strategies and Expressive ....... 50 Language

11. Dual Latent Growth Curve Model: Lower-Level Strategies and Receptive 51 Language

12. Dual Latent Growth Curve Model: Higher-Level Strategies and Expressive 52 Language

13. Dual Latent Growth Curve Model: Higher-Level Strategies and Receptive 53 Language

14. Bivariate Latent Difference Score Model: Lower-Level Strategies and 55 Expressive Language

15. Bivariate Latent Difference Score Model: Lower-Level Strategies and 57 Receptive Language 
16. Bivariate Latent Difference Score Model: Higher-Level Strategies and 58 Expressive Language

17. Bivariate Latent Difference Score Model: Higher-Level Strategies and .... 60 Receptive Language. 


\title{
ABSTRACT \\ IDENTIFICATION OF EFFECTIVE STRATEGIES TO PROMOTE LANGUAGE IN DEAF CHILDREN WITH COCHLEAR IMPLANTS
}

\author{
by \\ Ivette Cruz
}

Nova Southeastern University

A great deal of evidence suggests that parental communication and involvement are essential for the development of language in young children. However, hearing parents of deaf children face unique challenges in providing appropriate stimulation and language input to their deaf children. To date, few studies have determined which types of input are best. This study utilized data collected from the largest, youngest, nationally representative sample of deaf children receiving cochlear implants. The purpose of this study was to identify the facilitative language techniques that are most effective in facilitating receptive and expressive language development in young deaf children. Ninety-three deaf children, ages 2 years and under were enrolled at six implant centers. Deaf children were assessed prior to implantation and then followed for three years postimplantation. At each assessment, parent-child interactions were videotaped in an unstructured Free Play and structured Art Gallery task. All parent and child speech, vocalizations, and sign language were transcribed from the 10 minute videotaped parentchild interactions and coded using the Parenting Strategies for Communication coding system. Results revealed that the most frequently used lower-level strategies used by parents were directives, comments, and close-ended questions. The most frequently used higher-level strategies were parallel talk, open-ended questions, and recast. In addition, 
the Art Gallery task facilitated more parent utterances and longer mean length of utterances compared to Free Play, but the frequency of facilitative language techniques was not different. Using bivariate latent difference score modeling, higher-level strategies predicted growth in expressive language scores across three years post-implantation. Further, higher-level strategies had a delayed effect on receptive language, with techniques used at 24 months post-implantation predicting growth in receptive language at 36 months post-implantation. These results suggested that parent's play an active role in facilitating their child's language development. Interventions for parents should be developed using a coaching model, where parents receive hands-on training and practice using these effective facilitative language techniques. Future studies should evaluate the effectiveness of this intervention, as well as the effectives of these language techniques in children implanted after 2 years of age. 


\section{CHAPTER I}

\section{Statement of the Problem}

From the earliest point in development, communication between an infant and caregiver forms the foundation for critical aspects of growth. Developmental studies have confirmed that language and communication are the earliest and most important environmental forces for the development of cognition, affect, and social interaction (Bloom, 1998). Evidence indicates that normal development requires some level of effective communication, and lack of communicative ability has cascading consequences for cognitive, behavioral, and social development. Thus, for children with significant hearing losses, difficulties with communication present a substantial threat to optimal development, such as behavior problems, emotional difficulties, poor academic achievement, and difficulties with visual attention (Marschark, 1993; Quittner, Leibach, \& Marciel, 2004; Quittner, Smith, Osberger, Mitchell, \& Katz, 1994; Smith, Quittner, Osberger, \& Miyamoto, 1998).

Ninety percent of children with sensory neural hearing losses (SNHL) are born to hearing parents (National Institute on Deafness and Other Communication Disorders, 2000), thus an immediate "mismatch" between the hearing status of the child and parent (Gregory \& Hindley, 1996; Quittner et al., 2004) presents a significant barrier to effective communication (Meadow-Orlans \& Spencer, 1996). For children who are severely to profoundly deaf, cochlear implant surgery may facilitate the development of oral language. Hearing parents of children who are severely to profoundly deaf and who choose oral language as their primary mode of communication have better opportunities than in previous years to develop their children's oral language skills with the use of a 
cochlear implant. Recent research suggests that deaf children using cochlear implants have made significant gains in language following implantation; however, despite these encouraging results, there is significant variability in their language outcomes even after accounting for child age and length of implant use (Duchesne, Sutton, \& Bergeron, 2009). Family variables, such as parental linguistic input, may partially account for these individual differences in the outcomes of young deaf children. To date, few studies have evaluated the impact of parental input, on deaf children's language development. The current study aimed to identify the communicative parenting strategies or facilitative language techniques that are most effective in fostering language development in young deaf children. Facilitative language techniques are strategies that parents or educators use to promote language in children who are deaf or have language delays. 


\section{CHAPTER II:}

\section{Review of the Literature}

\section{Childhood Deafness}

Deaf parents with deaf children may use sign language or nonverbal gestures to communicate with their child and are more likely to wait for the child to observe them before signing or responding to the child (Koester, Papousek, \& Smith-Gray, 2000). Such coordination is important for the deaf child who must rely on vision for both receptive input and for exploration of the external world (Koester et al., 2000; Waxman \& Spencer, 1997). In contrast, hearing parents of deaf children find early communication difficult and often develop minimal skills in the use of sign language (Kluwin \& Stinson, 1993). Thus, children with SNHL are at increased risk for delays in development. Children who are deaf have higher parent reported and observed behavior problems compared to normal hearing children. In addition, they also exhibit poorer sustained and visual attention when compared to normal hearing children (Barker, Quittner, Fink, Eisenberg, Tobey, \& Niparko, 2009). However, for those parents who provide a language enriched environment early on for their child, there is evidence that this leads to the most ageappropriate cognitive, social, and behavioral development (Barker et al., 2009; Grimley, Barker, Cruz, \& Quittner, 2009; Marschark \& Spencer, 2003; Marschark, 1993).

For both hearing and deaf children, vocalizations by parents have been shown to shape emerging language skills and play a critical role in furthering interactions between parents and their children. These vocalizations are important even before infants are able to imitate language because they provide important affective information and cues to help the infant identify objects and people in the social world (Koester et al., 2000). Studies 
have also demonstrated that both the quantity and quality of maternal input are associated with better receptive and expressive language development (Kaiser, Hancock, \& Hester, 1998). Exposure to language input at home has been associated with increased vocabulary (Huttenlocher, Haight, Brykm Seltzer, \& Lyons, 1991), and parents who comment on objects and events in the child's visual field have better receptive and expressive language than those whose parents simply redirect and label objects (Kaiser \& Hancock, 2003).

Children who are born with moderate to severe hearing loss experience significant early (i.e., prelingual) auditory deprivation, placing them at a significant disadvantage in establishing the early precursors of oral language that lead to vocabulary development and later skills related to morphology and syntax. Children with hearing losses tend to be delayed in their verbal skills, academic achievement, and social development (Davis, Bamford, Wilson, Ramkalawan, Forshaw, \& Wright, 1997). Hearing loss also appears to influence reading and writing skills. The reading progress of a hearing impaired child is approximately one half of one grade per year, with a plateau at third or fourth grade and the mean reading level of the average 18 year old with severe-to-profound SNHL is similar to a 9-10 year old (LaSasso \& Mobley, 1996; Paul, 1998).

These language delays are likely due to both early auditory deprivation and different patterns of interactions with caregivers (Spencer, 1991). Several observational studies have shown that mothers in "mismatched dyads" tend to be more intrusive and directive in their interactions (Koester et al., 2000; Lederberg \& Prezbindowski, 2000; Marschark, 2000), which may impact language development, attention, and parent-child attachment (Bornstein, 2000). Thus, the language delays seen in deaf children may be 
due, in part, to challenges hearing parents have in making necessary adaptations to their deaf child or providing the scaffolding needed to help their children gain knowledge and communicative competence (Koester et al., 2000; Wood, 1991). A primary aim of this study was to assess these dyadic interactions in a series of videotaped tasks to determine which strategies are most effective in promoting language development. Identification of these strategies may ultimately form the basis of an early intervention program targeting early parent-child communication in families of deaf children.

Recent studies of children with significant hearing losses have begun to identify the parental communicative strategies that are most strongly associated with later language development (e.g., imitation, expansion, questioning, parallel talk) (DesJardin \& Eisenberg, 2007; Girolametto, Weitzman, Wiigs, \& Pearce, 1999). The current study sought to identify the communicative parenting strategies that are most effective in facilitating language development in a large cohort of deaf children younger than 2 years of age. This information is needed to develop effective early intervention strategies for deaf children who receive a cochlear implant or some other type of amplification device.

\section{Cochlear Implants}

Prior to the introduction of cochlear implants in the 1980s, hearing aids were the only means by which children with SNHL could access auditory information. However, despite this type of amplification, a majority of severely to profoundly deaf children still showed delays in communication when compared to hearing peers. Specifically, children with hearing aids increased their expressive language skills at less than half the rate of their hearing peers (Svirksy, 2000). In addition, at the age of 5 years, children who do not receive a cochlear implant were approximately 3 years delayed in expressive language 
compared to normal hearing children (Svirsky, Robbins, Kirk, Pisoni, \& Miyamoto, 2000).

To date, cochlear implants have demonstrated tremendous promise in school-age deaf children. To be a candidate for cochlear implantation, children must have a bilateral severe to profound hearing loss and have received only marginal benefit from amplification. In comparison to hearing-aids, which amplify sounds to the middle ear which are then transmitted to the inner ear, cochlear implants send electrical signals to the inner ear and directly stimulate the auditory nerve. This is accomplished by surgically implanting an electrode array in the cochlea (see Figure 1). The external components of the cochlear implant include a headpiece with a microphone and a speech processor. The speech processor converts acoustic information entering the microphone into electronic codes, which are then transmitted through the skin to the implanted cochlear stimulator and onto the electrode array. Electrodes stimulate the nerve endings within the cochlea sending these stimuli to the brain which are eventually interpreted as sound (Wilson, 2008). Following implantation, children need to learn how to decode and interpret these sounds by way of parental input and frequent training by speech and language pathologists and audiologists.

\section{Cochlear Implant Outcomes}

Although several studies indicate that cochlear implants are associated with significant gains in language, most have been conducted at single centers with small samples and few minority children. Parents report that the primary reason for seeking cochlear implantation is to promote the development of spoken language (Fink, Wang, Quittner, Eisenberg, Tobey, \& Niparko, 2007; Kluwin \& Stewart, 2000). In general, 


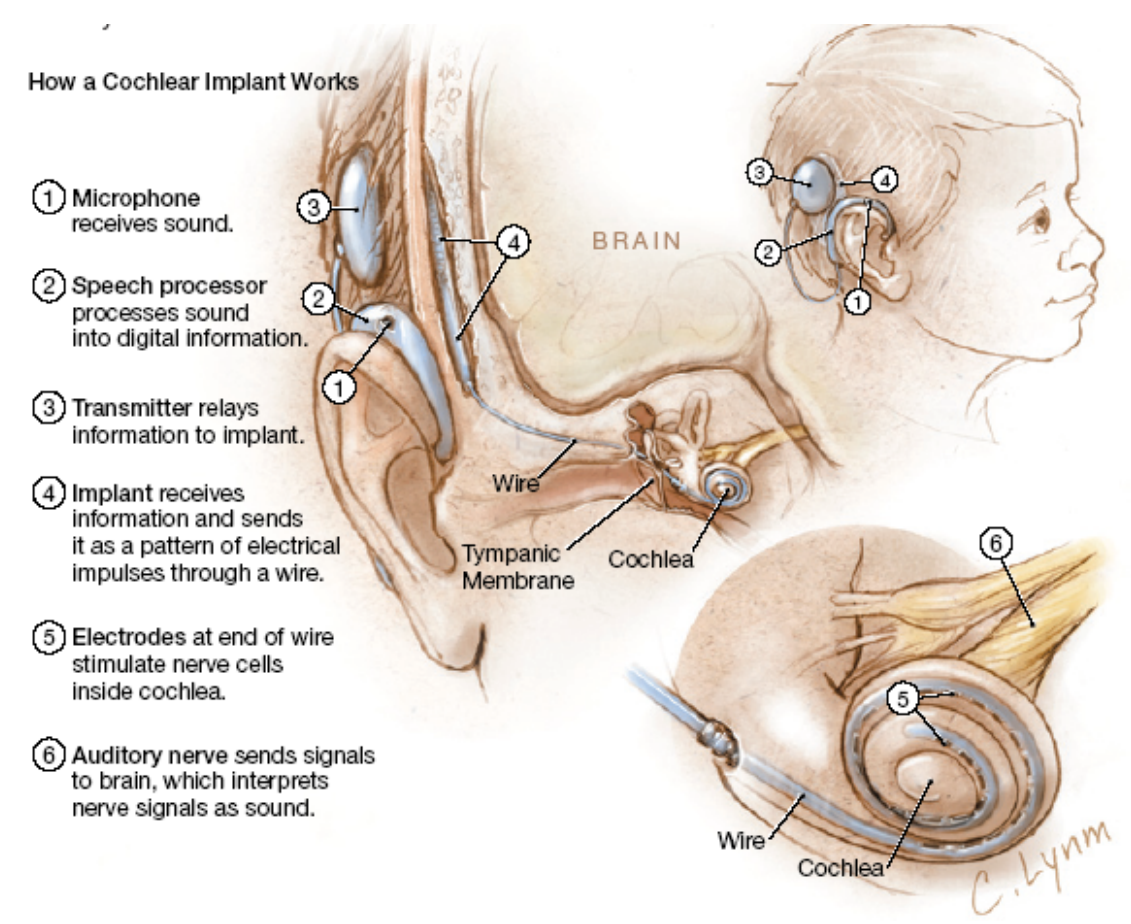

Figure 1. Description of how a cochlear implant functions. Figure was obtained from the following reference: Parment, S., Lynm, C., \& Glass, R. (2004). Cochlear Implants.

Journal of the American Medical Association, 291(9), 2398. Copyright (C) (2004)

American Medical Association. All rights reserved. 
children with cochlear implants make significant gains in speech perception, speech recognition, and expressive and receptive language following implantation (Baldassari, Schmidt, Schubert, Srinivasan, Dodson, \& Sismanis, 2009; Cohen, Waltzman, Roland, Staller, \& Hoffman, 1999; Svirsky et al., 2000); however, there is a great deal of variability in these language outcomes. The current study consisted of the largest, youngest, and most nationally representative sample of children with cochlear implants, recruiting participants from six cochlear implant centers. This study followed children for three years post-implantation and aimed to identify the most effective linguistic language techniques associated with growth in language.

Earlier research focused on the improvements in speech recognition. In a small sample of profoundly hearing-impaired children ages 20 months to 15 years $(\mathrm{N}=19)$, children showed significant improvements in speech recognition on 6 different measures 3 to 12 months post-implantation (Cohen et al., 1999). However, these results should be interpreted with caution. Although this study attempted to follow children for 12 months, only two children completed the 12 month assessment, and only half completed the 6 month assessment. Moreover, this study had additional limitations, including a small sample size, data collection at a single center, and lack of demographic information (e.g., ethnicity, family income).

More recent research has focused on growth in expressive language. In a longitudinal study of 70 children (mean age at implantation was 4.5), cochlear implant users showed greater gains in expressive language than those without an implant over a period of 30 months (Svirsky et al., 2000). Moreover, some children displayed expressive language scores similar to normal hearing peers. However, the average results concealed 
the variability in these outcomes. Although some achieved expressive language scores on the Reynell that were comparable to norms for hearing children, some children remained severely delayed even after more than 2 years of implantation (1 to 2 standard deviations below norms). In addition, although this study recruited a sample of 70 children, not all children completed each assessment point. Specifically, less than $40 \%$ of the sample was included in the 12 to 20 month assessment points, and only 20 children completed the 30 month assessment point. Further, this study lacked a control group and therefore, comparisons were made to a sample of children with hearing aids from another study, as well as normative data on the Reynell expressive language scales. This was a weakness for this study, as a control group would have provided a more accurate estimate of expected growth in expressive language following cochlear implantation, while also comparing their expressive language to normal hearing children.

Other studies have examined receptive language. In a recent study of 36 children with profound bilateral prelingual hearing loss between the ages of 6 months and 12 years, children with cochlear implants had significantly higher language scores than norms presented for children with hearing aids on the Test of Auditory Comprehension (TAC; Baldassari et al., 2009). However, children with cochlear implants continued to show a 14-month delay in receptive language as assessed by the TAC. Specifically, only $26 \%$ of children had TAC total age-equivalent scores in the average range for hearing peers. On another measure of receptive language, the Bracken Basic Concept Scale (BBCS), the mean total score on the BBCS was within one standard deviation of children with normal hearing. Results indicated that $52 \%(\mathrm{n}=12)$ of implanted children achieved a score on the BBCS that was within the average range for normal hearing children. 
However, results were variable with three children (13\%) scoring less than 70 (2 standard deviations below average) and three children (13\%) scoring greater than 100 (1 standard deviation above average). This study had several limitations, including small sample size, lack of control group, cross-sectional design, and a wide range of time elapsing between implantation and study assessments (6 months to 5 years post-implantation).

Age at implantation also appears to be important. Studies have demonstrated that children implanted earlier have better language outcomes than children implanted later in life. For example, in a sample of 106 infants and toddlers Dettman, Pinder, Briggs, Dowell, and Leigh (2007) reported that children implanted during the first year of life had faster rates of receptive and expressive language development than children implanted during the second year of life (Dettman et al., 2007). Specifically, this study found that the average rate of growth for Language Comprehension (LC) on the Rossetti Infant-Toddler Language Scale (RI-TLS) was 1.12 for children implanted before 12 months of age compared to 0.78 for children implanted 12-24 months of age. This same pattern was also found for Language Expression (LE) on the RI-TLS; average rate of growth for children implanted before 12 months of age was 1.01 compared to 0.73 for children implanted between 12-24 months of age. However, this study was retrospective and although they reviewed files for 106 children, only 11 children implanted before 12 months of age and 36 children implanted between 12-24 months of age completed two or more RI-TLS yearly language assessments. In addition, only 19 children were implanted before 12 months of age compared to 87 implanted between 12-24 months of age. Their sample also decreased substantially after removing children with mild, moderate, and severe cognitive delays $(n=41)$. 
Children with cognitive delays tend to progress more slowly than children with average cognitive functioning in the areas of speech perception and language (Dowell, Dettman, Blamey, Barker, \& Clark, 2002; Dettman, Tomov, Dowell, Barker, Hughes, Williams, \& Saldic, 2003); therefore, these children were removed from analyses in the study previously described as they could potentially reduce the average rate of growth of expressive and receptive language. Results indicated that removing children with mild, moderate, and severe cognitive delays improved the mean rate of growth in language; however, children implanted after 12 months of age continued to have a slower growth rate than children implanted prior to 12 months of age (Dettman et al., 2007). In the current study, children with significant cognitive impairment (i.e., a Bayley Mental or Motor score of less than 70 or Leiter International Performance Scale - Revised [LeiterR] score of less than 66) were excluded. However, to increase the generalizability of the findings to a broader population of children receiving cochlear implants, this study included children with scores above 70 and 66 on cognitive measures.

A second study of 96 children with congenital bilateral profound SNHL implanted before the age of 4 reported similar results (Holt \& Svirsky, 2008). Children were followed for 2 years after device activation and were divided into 4 groups: Group 1 included children implanted between 6-12 months of age, Group 2 included children implanted between 13-24 months of age, Group 3 included children implanted between 25-36 months of age, and Group 4 included children implanted between 37-48 months of age. In general, age at implantation influenced the rate of both receptive and expressive language acquisition; children implanted earlier had faster rates of spoken language acquisition than those implanted later in life. Children implanted between 13-24 months 
of age performed better than children implanted later on the Reynell expressive and receptive language scales and on a word recognition task. However, the advantage of implanting children before 12 months of age compared to 12-24 months of age was only evident in receptive language scores on the Reynell, but not on expressive language or word recognition as measured by a Mr. Potato Head task. These results should be interpreted with caution because only 6 children were implanted at 6-12 months of age, resulting in a small sample size that may have affected the results. In addition, all children were recruited from a single center in Indiana, primarily Caucasian and thus, under represent minority children.

Despite these generally positive findings, most studies report substantial variability in language outcomes, even after accounting for child age and length of implant use. For example, over $50 \%$ of children remain severely delayed even after more than 2 years of experience with their cochlear implant (Svirsky et al., 2000). A recent study of 27 French-speaking children implanted between one and two years of age, found that although as a group, children exhibited language levels within normal limits on standardized measures (RDLS, Peabody Picture Vocabulary Test, Test of Auditory Comprehension, One-Word Picture Vocabulary Test), a closer examination revealed different language profiles (i.e., summary or analysis of language data) which ranged from "normal" to "language delayed" (Duchesne et al., 2009).

Specifically, only $56 \%$ of children scored within normal limits on receptive vocabulary, $86 \%$ on expressive vocabulary, $86 \%$ on comprehension of concepts, $43 \%$ on comprehension of morphemes, and $36 \%$ on comprehension of syntactic constructions. Furthermore, scores varied significantly from above the $60^{\text {th }}$ percentile to below the $20^{\text {th }}$ 
percentile. A closer examination of individual patterns in a subset of children $(n=14)$, revealed that only 4 children (29\%) scored within normal limits on all measures, compared to $71 \%$ that scored within the delayed range on at least one measure. Moreover, children's whose language abilities were within normal limits were not necessarily those who had been implanted earlier or used their implant over a longer period of time. These researchers concluded that early implantation does not ensure that children will obtain language abilities within normal limits and that factors, such as communication mode, educational placement, cognitive abilities, and parental involvement may impact language outcomes in children with cochlear implants (Duchesne et al., 2009).

In sum, significant questions about the efficacy of cochlear implants for deaf children need to be answered. For example, one such question is, what proportion of children develop oral language following implantation and how can we best facilitate use of an implant? A number of variables may contribute to individual differences in outcomes, including family factors such as parenting stress, maternal sensitivity, and parental linguistic input (Kirk, Miyamoto, Ying, Perdew, \& Zuganelis, 2000; Quittner, Barker, Cruz, Snell, Grimley, \& Botteri, 2010).

\section{Parenting Stress}

One family-level variable that has been shown to affect children's development in general is parents' level of stress. Clinically elevated levels of parenting stress have been reported by hearing parents raising children who are deaf (Quittner et al., 2010; Quittner, Glueckauf, \& Jackson, 1990; Quittner, Steck, \& Rouiller, 1991; Singer, Song, Hill, \& Jaffe, 1990; Wolf, Noh, Fisman, \& Speechley, 1989). In a study of mothers caring for 
children with severe to profound hearing losses, $65 \%$ scored at or above the clinical cutoff on a standardized measure of child-related stress compared to $25 \%$ of mothers in the normal hearing group (Quittner et al., 1990). These parents also reported more difficulty in maintaining family routines and engaging in parenting activities. Furthermore, these parents endorsed communication difficulties with their children as the most significant stressor (Quittner et al., 2010). Similarly, high levels of parenting stress have been reported by mothers of children with cochlear implants and hearing aids in comparison to normal hearing dyads (DesJardin, 2003a). Across several studies, mothers have rated their deaf children as more demanding, hyperactive, moody and less adaptable than mothers of hearing children (Barker et al., 2009; Quittner et al., 1990). Deaf children have also been found to exhibit more behavior problems on the Child Behavior Checklist (CBCL), including elevations on internalizing, externalizing behavior problem scales and attention (Barker et al., 2009; Mitchell \& Quittner, 1996).

In the first multi-center, large-scale study of the effects of cochlear implants on deaf children's development, higher levels of deaf-specific parenting stress on the Parenting Stress Index (PSI; Abidin, 1983) were found in comparison to hearing children (Quittner et al., 2010). This study used the same sample as this proposed one, which includes 188 deaf children and 97 hearing controls recruited from 6 implant centers and 2 preschools. In this study, a context-specific measure of parenting stress was used to assess the unique challenges faced by parents of deaf children. In a rank ordering of highest ranked stressors, communication difficulties, educational concerns, maintaining hearing aid devices, medical/audiological care, and having to be a language teacher for their child were among the top five most stressful. Moreover, both parent-reported and 
observed behavior problems were higher in the deaf compared to hearing group and language delays fully mediated the relationship between hearing status and child behavior problems. In addition, language delays and child behavior problems partially mediated the relationship between hearing status and parenting stress.

In sum, parents of hearing-impaired children have consistently reported higherlevels of stress in caring for their deaf children, making daily routines and activities more difficult. Parents rated their communication with their child as the most significant challenge. This study sought to identify which linguistic language techniques are most effective in facilitating use of an implant (language growth), which may indirectly reduce parenting stress by assisting parents in communicating effectively with their deaf child.

\section{Maternal Sensitivity}

Another likely contributor to the variability in language outcomes following cochlear implantation is the quality of parent-child interactions. Early in development, these interactions are a key source of emotional attachment, provide scaffolding for the development of important cognitive and behavioral skills, and provide critical opportunities for communicative experiences (Bakeman \& Adamson, 1984; Sroufe, Egeland, \& Carlson, 1999; Vygotsky, 1962). Observational studies have shown that, relative to mothers in hearing dyads, hearing mothers of deaf children tend to be more controlling in their verbal and non-verbal interactions (Quittner et al., 2007), spend less time in coordinated joint attention with their child (Spencer \& Waxman, 1995), and have greater difficulty responding to the child's emotional and behavioral cues (Swisher, 2000). The consequences of these disruptions include less secure attachment, difficulties sustaining attention and exerting behavioral control, and slower development of 
communicative competence (Bornstein, 2000; Bornstein, Haynes, \& Painter, 1998;

Lederberg \& Prezbindowski, 2000).

Quittner and colleagues (2007) have also found that general parental sensitivity or "attunement" (e.g., warmth, child-centered play, appropriate scaffolding) contributes to better outcomes for young deaf children receiving a cochlear implant. Maternal sensitivity was assessed in 20 minutes of video-taped parent-child interactions, including one unstructured (i.e., free play) and two structured (i.e., puzzle solving, art gallery) tasks. Specifically, maternal sensitivity predicted changes in receptive and expressive language; mothers who were more sensitive had children who performed better on standardized measures of language and communication (Quittner et al., 2007). Other research has suggested that the amount and quality of parental language scaffolding contributes to better language outcomes for these children (Girolametto et al., 1999). Moreover, cognitive and linguistic stimulation were significantly associated with the development of speech production in the first year following implant activation (Grimley et al., 2009). These findings suggest that the quality of parent-child interactions may be significantly associated with better language outcomes. Less is known, however, about the specific parenting behaviors that contribute to this improvement.

\section{Parental Linguistic Input}

Recent rehabilitation programs have also highlighted the important role parents play in facilitating oral language development in children with cochlear implants (Cook, Tesier, Klein, \& Armbruster, 2000; Estabrooks, 2007; Garber \& Nevins, 2007; Lim \& Simser, 2005; Sandall, Hemmeter, Smith, \& McLean, 2005). These rehabilitation programs are based on the social interactionist theory of language development, which 
postulate that young children learn language in the contexts of their daily experiences and particularly through interactions with their caregivers and family (Chapman, 2000; Hoff, 2000). Generally, the adult's role is to provide linguistic input that is appropriate for the child's developmental level. As the child's language skills increase, the adult provides more complex input and less support, allowing the child to take more control over this learning process.

Variation in the language skills of young deaf children (Fewell \& Deutscher, 2004; Hart \& Risley, 1995; Weizman \& Snow, 2001) and children with cochlear implants (DesJardin \& Eisenberg, 2007) are strongly linked to parental linguistic input in terms of both quantity (e.g., number of different words or vocabulary diversity, mean length of utterance) and quality (e.g., facilitative language techniques). Generally, children who are provided with a variety of words and phrases (e.g., utterances), slightly above their language level, develop better language skills. These linguistic constructs have been shown to positively correlate with important indicators of later school achievement (Catts, Fey, Tomblin, \& Zhang, 2002; Hart \& Risely, 1999).

Facilitative language techniques are strategies that parents and educators use to promote language in children who are deaf or have language delays. These techniques can be used with children from infancy to school age and can be modified according to the child's language ability and/or age. In previous literature, facilitative language techniques have been divided into two categories, lower versus higher-level strategies. Lower-level strategies consist of linguistic mapping (putting into words what the child may be trying to communicate), imitation (repeating child's utterance), labeling (naming an object, picture, etc), and closed-ended questions. Higher-level strategies include open- 
ended questions, expatiation (expanding on the child's utterance), and recast (changing child's utterance into a question). To date, only one coding scheme has been developed to systematically evaluate facilitative language techniques during parent-child interactions (DesJardin, 2003b).

Furthermore, while some language techniques (e.g., linguistic mapping, imitation) enhance language learning in young children at the single-word stage of language development (Warren,Bredin-Oja, Escalaned, Finestack, Fey, \& Brady, 2006), others (e.g., recast, open-ended questions) provide support for children performing at the twoto-three word level (Girolametto \& Weitzman, 2006; Kaiser \& Hancock, 2003). Parental linguistic input that is "fine-tuned" (tailored to the child's language level) can accelerate spoken language development (Chapman, 2000; Yoder \& Warren, 1998). For example, a mother may begin a conversation by asking her child an open-ended question and if the child does not respond, the mother might revert to a lower-level, closed-ended question. In contrast, providing lower-level techniques when the child is at a higher language level may hinder the child's language development. The current study will provide systematic data on how parents use and modify their facilitative language techniques from one to three years post-implantation.

\section{Facilitative Language Techniques}

During the critical stages of language development, particular techniques are essential for developing more complex language. Facilitative language techniques, such as open-ended questions, encourage conversation. In contrast, linguistic mapping and imitation are more didactic in nature and are more appropriate for children who are at the pre-linguistic and one-word level of language development (Girolmaetto et al., 1999; 
Yoder, McCathren, Warren, \& Watson, 2001). To date, only two studies have investigated which linguistic parenting strategies are related to better language outcomes in children with cochlear implants.

The first study was conducted in a sample of 32 parent-child dyads with children ranging in age from 2.5 to 7.2 ; children had bilateral profound SNHL aided by multichannel cochlear implants (DesJardin \& Eisenberg, 2007). On average children were implanted at 34 months of age and assessed at 24 months post-implantation. In this study, parents' facilitative language techniques were coded during videotaped parent-child interactions (i.e., free play, 2 storybook activities) and language was measured using the Reynell Developmental Language Scales. The use of higher-level language techniques, such as recast, were positively associated with children's receptive language abilities, while the use of open-ended questions was positively related to children's expressive language skills. In contrast, lower-level techniques, such as linguistic mapping, were negatively correlated with children's language abilities. This study also found that mother's quantitative linguistic input, such as mean length of utterance (MLU), was associated with children's language skills. Although this study provided useful information on the effects of facilitative language techniques for children with cochlear implants, it had significant limitations, including a small sample size, data collected at a single implant center, a cross-sectional design and large age range. In addition, the amount of time spent with the cochlear implant varied from 3 to 60 months postimplantation. Moreover, this study was only able to report on the relationship between facilitative language techniques and language scores and did not report on the effect of the strategies on language. The current study expanded on these results by identifying the 
facilitative language techniques that predict growth in language 3 years postimplantation. In addition, this proposed study included a large, nationally representative sample of children under 2 years of age from 6 implant centers and 2 preschools.

The second study examined the relationship between early factors that may influence children's phonological awareness and reading skills over a three year period (DesJardin, Ambrose, \& Eisenberg, 2009). This study was an extension of the one previously described; fifty percent of those children $(n=16)$ who participated in the previous study were included. Consistent with previous findings, results indicated that mothers' facilitative language techniques during 20 minutes of video-taped story book activities were associated with their children's later phonological awareness and reading abilities. Specifically, higher-level techniques, such as open-ended questions were related to better phonological awareness. Open-ended questions were also positively associated to better letter-word identification and passage comprehension. Recasting, a higher-level facilitative technique, was also related to better reading achievement (oral vocabulary and reading vocabulary) (DesJardin, Ambrose, \& Eisenberg, 2009). In contrast, lower-level strategies, such as linguistic mapping, were negatively correlated with phonological awareness and reading achievement (letter word identification, reading vocabulary). Furthermore, mothers of children with higher language scores on the Reynell or Oral Written Language Scales (OWLS) used more higher-level facilitative strategies than those with lower language scores (DesJardin, Ambrose, \& Eisenberg, 2009). Although this study provided important information, its sample size, use of different language measures at each time point, and wide range of ages, limited researchers' conclusions. Moreover, facilitative language techniques were only evaluated at one time point and 
length of implant use varied for the sample (12 - 44 months at first assessment). The current study evaluated the effects of linguistic language techniques on growth in language at 12, 24, and 36 months post-implantation.

\section{Purpose of the Study}

Despite the generally positive results associated with early cochlear implantation, there is limited data on which clinical, rehabilitative, and educational strategies enable cochlear implant users to achieve their greatest potential in acquiring oral language. This study evaluated parents' linguistic input in "mismatched" parent-child dyads (i.e., hearing parents of deaf children) over 3 years following cochlear implantation. This sample was drawn from the largest, nationally representative, and youngest sample of deaf children with cochlear implants. The goals of the study were to identify which parental communicative strategies, such as parallel talk, expansion, and open-ended questions, were most effective in facilitating the development of language and communication in deaf children following cochlear implantation. A secondary goal of this study included, incorporating these strategies into early intervention and rehabilitation programs for hearing-impaired children, if empirical support for particular parental communication strategies is garnered.

\section{Study Aims \& Hypotheses}

The major aim of this study was to identify the facilitative language techniques used by parents that are associated with growth of oral language. Based on prior research, it was hypothesized that higher-level facilitative language techniques, such as recast and open-ended questions, would be more effective in fostering growth of language compared to lower-level strategies, such as imitation. Another major aim of this study was to assess 
the facilitative language techniques used by parents of young deaf children at baseline (prior to implantation) and for 3 years post-implantation. Over the 3 years of longitudinal assessments, parents were expected to use increasingly "higher-level" communication strategies in their dyadic interactions. It was hypothesized that "lower-level" strategies (e.g., labeling) would be used more frequently for children prior to implantation and "higher-level" strategies (e.g., open-ended questions) would be used more frequently for children post-implantation. Secondary aims of this study included, describing the most frequent facilitative language techniques used by parents of hearing-impaired children under two years of age and comparing the types of facilitative language techniques used in a structured (Free Play) and unstructured task (Art Gallery). 


\section{CHAPTER III:}

\section{Method}

\section{Participants}

Participants were part of a larger study, the Childhood Development after Cochlear Implantation Study (CDaCI), a multi-center, national cohort investigation of the effectiveness of pediatric cochlear implants (Quittner et al., 2004). This is the largest and youngest sample of cochlear implant candidates that have been studied longitudinally. Participants were recruited from six clinical implant centers (Los Angeles, CA; Baltimore, MD; Miami, FL; Ann Arbor, MI; Durham, NC; Dallas, TX ) and two preschools (Baltimore, MD; Dallas, TX)that enrolled hearing children (Fink et al., 2007). The full $\mathrm{CDaCI}$ cohort consisted of 188 and 97 hearing children (for complete demographics of the CDaCI cohort see Fink et al., 2007).

Inclusion criteria for children in the $\mathrm{CDaCI}$ study were: 1) age under 5 years, 2) severe to profound sensorineural hearing loss, and 3) parents committed to educating the child in spoken English. Exclusion criteria included significant cognitive impairment (i.e., a Bayley Mental or Motor score of less than 70 or Leiter International Performance Scale - Revised (Leiter-R) score of less than 66; Bayley, 1993; Roid \& Miller, 1991). Children with minor cognitive deficits were included to increase the generalizability of the findings to a broader population of children receiving cochlear implants. Participants in both the deaf and hearing group were assessed at Baseline (two to four weeks prior to implantation for the deaf group) and every six months (from point of activation for deaf group) for three years. Institutional review boards at all centers approved the study protocol. 
Enrollment began in October 2002 and continued through December 2004. Four hundred and twenty-five CI candidates were screened, 268 children were eligible for the study and 188 consented to participate across six cochlear implant sites. Forty-four percent of the screened sample was enrolled.

For the current study, only children 2 years and younger were included $(n=93$;

See Table 1). Demographic differences in the younger and older deaf cohorts were evaluated with $t$-tests for continuous variables and chi square tests for categorical variables. They did not differ on gender, ethnicity, parental education, household income, cause of hearing loss, or primary communication mode. The younger and older subsamples primarily differed on variables influenced by age. Specifically, they differed on onset of deafness, age at diagnosis, and age at first amplification, with the younger subsample having an earlier onset, were younger at diagnosis, and also younger at first amplification use $(t(178)=-3.78, p<.001 ; t(186)=-8.18, p<.001 ; t(186)=-9.02, p<.001)$. Differences were also found on Pure Tone Average, the average of hearing sensitivity (PTA4) for the better ear and etiology of deafness, with higher PTA4 and congenital onset in the younger subsample $\left(t(183)=2.89, p<.01, \chi^{2}(2)=18.58, p<.001\right)$.

\section{Procedure}

After an initial medical screening for children in the deaf group, a baseline assessment was scheduled for two to four weeks prior to cochlear implant surgery. This assessment was conducted by a speech/language pathologist either at the implant center or, in the case of one of the preschools from which hearing controls were recruited, at the preschool itself. The assessment was typically conducted during two half-day appointments to lessen fatigue for the child and family. During the first day, parents 
Table 1

\section{Demographics}

\begin{tabular}{|c|c|c|}
\hline \multicolumn{2}{|l|}{ Characteristic } & Young Deaf Children $(\mathrm{n}=93)$ \\
\hline \multicolumn{2}{|c|}{$\begin{array}{ll}\text { Age (months) } & \text { Mean age (SD) }\end{array}$} & $14.51(4.72)$ \\
\hline \multicolumn{2}{|c|}{ Age of onset of hearing loss (months) } & $0.82(2.59)$ \\
\hline \multicolumn{2}{|l|}{ PTA4 (better ear) } & $109.56(15.42)$ \\
\hline \multicolumn{2}{|c|}{ Age at diagnosis (months) } & $5.14(5.36)$ \\
\hline \multicolumn{2}{|c|}{ Age at first hearing aid use (months) } & $7.38(5.63)$ \\
\hline \multirow{3}{*}{ Onset of hearing loss } & Sudden & $7 \%(6)$ \\
\hline & Progressive & $20 \%(19)$ \\
\hline & Congenital & $72 \%(67)$ \\
\hline \multirow[t]{8}{*}{ Cause of hearing loss } & Genetic & $32 \%(30)$ \\
\hline & Aminoglycosides & $1 \%(1)$ \\
\hline & Cytomegalovirus & $1 \%(1)$ \\
\hline & Hyperbilirubinemia & $3 \%(3)$ \\
\hline & Meningitis & $5 \%(5)$ \\
\hline & Prematurity & $1 \%(1)$ \\
\hline & Other & $1 \%(1)$ \\
\hline & Unknown & $55 \%(51)$ \\
\hline \multirow[t]{2}{*}{ Gender \% (n) } & Male & $54 \%(50)$ \\
\hline & Female & $46 \%(43)$ \\
\hline \multirow[t]{4}{*}{ Race } & White & $81 \%(75)$ \\
\hline & African-American & $9 \%(8)$ \\
\hline & Asian & $3 \%(3)$ \\
\hline & Other & $8 \%(7)$ \\
\hline \multirow[t]{2}{*}{ Ethnicity } & Hispanic & $15 \%(14)$ \\
\hline & Non-Hispanic & $84 \%(78)$ \\
\hline \multirow[t]{5}{*}{ Communication Mode } & Speech & $24 \%(22)$ \\
\hline & Sign Language & $19 \%(18)$ \\
\hline & Simultaneous/Speech Emphasis & $23 \%(21)$ \\
\hline & Simultaneous/Sign Emphasis & $2 \%(2)$ \\
\hline & Other / Undecided & $32 \%(30)$ \\
\hline \multirow[t]{4}{*}{ Parents' education } & $<$ High school & $2 \%(2)$ \\
\hline & High school grad & $17 \%(16)$ \\
\hline & Some College & $28 \%(26)$ \\
\hline & College & $53 \%(49)$ \\
\hline \multirow[t]{6}{*}{ Parents' Income } & $<\$ 15,000$ & $3 \%(3)$ \\
\hline & $\$ 15-29,999$ & $13 \%(12)$ \\
\hline & $\$ 30-49,999$ & $20 \%(19)$ \\
\hline & $\$ 50-74,999$ & $19 \%(18)$ \\
\hline & $\$ 75-100,000$ & $18 \%(17)$ \\
\hline & $\$ 100,000+$ & $17 \%(16)$ \\
\hline
\end{tabular}


completed demographic and self-report measures of communication and behavior, and children were assessed with language measures, cognitive tests, and an audiological exam. On the second day, children participated in videotaped, free play, structured play and problem-solving tasks with and without parents, and parents completed psychosocial questionnaires about their children. All measures, including those related to language, were conducted in spoken English. Parents in the deaf group received a \$100 honorarium annually, travel stipends if required, and extended warranties for the implants as reimbursement for their time and effort; parents in the hearing group received the same honorarium. All written and videotaped materials were de-identified, replacing participant names with numbers to ensure confidentiality.

CI candidates were typically scheduled for surgery 2-4 weeks after the baseline assessment, with a return visit 4-6 weeks later for implant activation. Follow-up assessments were then conducted every 6 months. At each assessment point, the parentchild dyad completed the videotaped interaction tasks, along with a series of questionnaires. The yearly assessment points (Baseline, 12 months, 24 months, 36 months) and two of the four videotaped tasks were used in this study (i.e., Unstructured Free Play task, Structured Art Gallery task).

\section{Measures}

\section{Language}

Reynell Developmental Language Scales.(RDLS; Reynell \& Greuber, 1990):

The RDLS are commonly used, well-validated language scales for children one to seven years of age. They have been used with deaf and hearing children (DesJardin et al.,2009; Horn, Fagan, Dillon, Pisoni, \& Miyamoto, 2007; Laing, Law, Levin, \& Logan, 2002). 
This test also provided explicit instructions regarding adaptation of test administration for hearing-impaired children, which allows for testing in different communication modes. The measure consists of a Verbal Comprehension and Expressive Language scale. Both scales have acceptable split-half reliability coefficients across age groups ranging from 0.74 to 0.93 . Children's scores can be compared to normative data to produce either standard scores or language age.

\section{Videotaped Interactions}

Free Play Task. Free play tasks are commonly used to assess a variety of developmental processes, including the quality of parent-child interactions and parenting strategies (NICHD, 1999). In the present study, age appropriate toys were presented to each parent-child dyad. The parent and child were instructed to "play as you would at home," and their interactions were videotaped for 10 minutes. The first 5 minutes of this task was used in the current study.

Art Gallery Task. In the Art Gallery task, parents were asked to show the child a series of 5 art pictures that were mounted on the walls of the playroom at different heights. Parents were asked to talk about the pictures for a period of 5 minutes and determine which picture the child liked best and least. This task has been used in prior studies to assess parental sensitivity and communicative competence in children with atypical language development (Deckner, Adamson, \& Bakerman, 2003).

\section{Coding Videotapes Parent-Child Interactions}

Transcription of Videotaped Language Samples. All parent and child speech, vocalizations, and sign language from the 93 videotaped dyads were transcribed using the Codes for the Human Analysis of Transcripts (CHAT). Transcriptions were analyzed 
using the Computerized Language Analysis (CLAN) system (MacWhinney, 2000) across the 4 assessment points (tapes $=372$ ). To ensure accurate transcription of the parent and child utterances and/or sign language, all transcriptions were reviewed by two individual coders. Previous research has reported good agreement for the calculation of word-byword correspondence, ranging from 0.95 - 0.98 Cohen's kappa for both mother and child utterances and 88-93\% for mother and child sign language utterances.

Parenting Strategies for Communication (PSC; DesJardin, 2003; see Appendix A). Each parent's transcribed utterance (linguistic phrase or sentence) was coded for one of 11 possible facilitative language techniques during both the Free Play and Art Gallery tasks. Codes included imitation, linguistic mapping, closed and open-ended questions, and parallel talk (see Tables 2-3 for a complete description of codes). Interrater reliability was established by having $20 \%$ of the tapes coded by an additional trained rater. Interrater reliability, indicated good agreement with Cohen's kappa ranging from 0.79 to $0.88($ Mean $=0.84)$. Proportional scores for each facilitative language technique were calculated and used in the analyses in order not to penalize less talkative parents who used appropriate language techniques. Accordingly, proportional data were calculated by dividing the total number of uses of each language technique by the overall number of parental linguistic attempts, which produced a percentage for each strategy. 
Table 2

Description and Examples of Lower-Level Parental Facilitative Language Techniques

\begin{tabular}{|c|c|c|}
\hline $\begin{array}{l}\text { Facilitative Language } \\
\text { Technique }\end{array}$ & Description & Example \\
\hline Linguistic mapping & $\begin{array}{l}\text { Putting into words or interpreting the child's } \\
\text { intended message using the context as a clue } \\
\text { (child uses a preceding vocalization that is not } \\
\text { recognizable as an approximation of a word). }\end{array}$ & $\begin{array}{l}\text { Child hands mother a toy cat and vocalizes - } \\
\text { mother says, "kitty." } \\
\text { Child pushes the car away and vocalizes - } \\
\text { father says, "all done." }\end{array}$ \\
\hline Imitation & $\begin{array}{l}\text { Repeating verbatim the child's preceding } \\
\text { vocalization or verbalization without adding } \\
\text { any new words. }\end{array}$ & $\begin{array}{l}\text { Child says, "boy" and mother says, "yes boy." } \\
\text { Child says, "pretty doll" and mother says, } \\
\text { "pretty doll." }\end{array}$ \\
\hline Label & Stating the name for a toy, picture, or object. & $\begin{array}{l}\text { Grandmother says, "There is a doggie" or } \\
\text { "I see the fish in the water." }\end{array}$ \\
\hline Closed-ended question & $\begin{array}{l}\text { Stating a question in which the child can only } \\
\text { answer with a one-word response. }\end{array}$ & $\begin{array}{l}\text { Father asks child, "Is that your favorite?" or } \\
\text { "Do you like that picture?" }\end{array}$ \\
\hline
\end{tabular}


Table 3

Description and Examples of Higher-Level Parental Facilitative Language Techniques

\section{Facilitative Language} Technique

Parallel Talk

phrase

Expansion

Expatiation

Recast

\section{Description}

Example

\author{
Caregiver talks aloud about what the child is \\ directly doing, looking at, or referencing. \\ Child is looking directly at a the picture of a bumble- \\ bee and caregiver says, "The bumble-bee is flying \\ over the flowers."
}

Caregiver provides a phrase/question in which the child can answer using more than one word.

While looking at a picture, caregiver says,

Caregiver repeats child's verbalization providing Child says, "baby cry." and the caregiver says, a more grammatical and complete language model without modifying the child's word order or intended meaning.

Similar to expansion except caregiver adds new information.

Caregiver restates the child's verbalization into a question format. "What is happening in this picture?" or "What do you think the cowboy will do next?"

"The baby is crying."

While looking at the picture - child says, "swim water" and mother says, "Yes, we are going swimming in the beach. This summer we are going to the beach."

Child says, "grandma here" and the caregiver says, "Is grandma here? or "Do you think grandma is here?" 


\section{CHAPTER IV}

\section{Results}

\section{Statistical Procedure}

A series of bivariate latent difference score (LDS) models were used to evaluate the relationship between facilitative language techniques and language development (expressive and receptive) across 3 years post-implantation. In addition, bivariate LDS models were used to examine whether one variable predicted change in the other (McArdle, 1988; McArdle \& Hamagami, 2001; McArdle \& Nesselroade, 2002). Prior to fitting these bivariate models, univariate latent growth curve models for each variable were completed to model the change process. Then, bivariate latent growth curve models were modeled to determine whether facilitative language techniques and language were correlated (indicating that the change processes were related). Following these models, bivariate LDS models examined whether facilitative language techniques led to later change in expressive and receptive language scores, as measured by the Reynell. Because the change process could go in either direction (change in facilitative language techniques could predict subsequent change in language, or vice versa), parameters for each direction were estimated simultaneously (i.e., with facilitative language techniques as the predictor and then with language as the predictor).

Full information maximum likelihood estimation with Mplus software (Muthen \& Muthen, 2008) was used for all analyses. This procedure estimates the model parameters using all available information rather than deleting cases with incomplete data (Enders, 2001). Thus, families who did not complete all assessments were still utilized in these analyses. This decision was made to maximize power of finding effects across variables 
and time. Similarly, the focus was on creating a reliable parameter estimate for each variable as a predictor of the change in the other variables, rather than on estimating all possible curvilinear growth parameters. Thus, growth parameters for a linear pattern of change in the bivariate LDS models only were estimated, in order to keep the tests highly focused and not increase the Type I error rate by estimating too many parameters.

For descriptive purposes, goodness of fit for the models were recorded. Several goodness of fit indices were used, which can be broken down into absolute fit (how well the model reproduces the data) and predictive fit (goodness of fit in the hypothetical replication samples). Assessment of absolute model fit was based on the loglikelihood ratio chi-square. Moreover, predictive fit statistics, including the Akaike information criteria (AIC), which is a parsimony adjusted index (i.e., favors simpler models; lower values of the AIC indicate better fit), the Bayes Information criteria (BIC), which also penalizes model complexity (lower values of the BIC indicate better fit), and the root mean square error of approximation (RMSEA) were also utilized. There is not a standard cutoff for an acceptable fit on the AIC and BIC, but these numbers are included to facilitate comparison of fit indices across models. In general, good models have an RMSEA of .05 or less.

\section{Descriptive Statistics}

Table 4 presents descriptive statistics for the facilitative language techniques, Reynell language scores, total parent utterances, and mean length of utterance (MLU). Means and standard deviations for each variable are presented for each assessment point: baseline (pre-implantation), 12 months, 24 months, and 36 months post-implantation. For facilitative language techniques, descriptives are presented for each individual 
Table 4

Means and Standard Deviations for Facilitative Language Techniques \& Language Measures

\begin{tabular}{lrrrrrrrr}
\hline & \multicolumn{2}{c}{ Baseline } & \multicolumn{2}{c}{ 12 Month } & \multicolumn{2}{c}{ 24 Month } & \multicolumn{2}{c}{ 36 Month } \\
\hline & \multicolumn{1}{c}{ Mean } & \multicolumn{1}{c}{ SD } & \multicolumn{1}{c}{ Mean } & \multicolumn{1}{c}{ SD } & Mean & \multicolumn{1}{c}{ SD } & Mean & \multicolumn{1}{l}{ SD } \\
Lower Level Strategies (\%) & 74.60 & 9.54 & 61.85 & 9.83 & 56.12 & 10.94 & 50.47 & 10.70 \\
Linguistic Mapping (\%) & 0.40 & 0.92 & 1.07 & 1.35 & 1.17 & 1.40 & 0.72 & 1.23 \\
Comments (\%) & 23.53 & 7.62 & 15.91 & 5.63 & 12.61 & 6.01 & 11.88 & 6.35 \\
Imitation (\%) & 0.33 & 0.58 & 2.53 & 2.27 & 2.76 & 2.30 & 2.97 & 2.20 \\
Label (\%) & 6.90 & 4.79 & 4.80 & 3.77 & 2.54 & 2.71 & 2.20 & 2.56 \\
Directive (\%) & 26.81 & 12.70 & 21.97 & 9.46 & 19.13 & 9.77 & 15.34 & 9.38 \\
Closed-Ended Question (\%) & 16.63 & 8.02 & 15.57 & 5.95 & 17.91 & 6.47 & 17.92 & 6.63 \\
Higher Level Strategies (\%) & 24.68 & 9.71 & 37.87 & 9.86 & 43.65 & 11.09 & 49.31 & 10.66 \\
Open-Ended Question (\%) & 6.37 & 4.09 & 10.70 & 6.02 & 12.71 & 6.65 & 15.83 & 6.46 \\
Expansion (\%) & 0.02 & 0.11 & 0.76 & 1.19 & 1.60 & 1.44 & 1.98 & 1.55 \\
Expatiation (\%) & 0.01 & 0.07 & 0.53 & 0.81 & 0.72 & 0.73 & 1.03 & 1.05 \\
Recast (\%) & 0.00 & 0.04 & 0.94 & 1.38 & 3.87 & 3.05 & 5.54 & 4.00 \\
Parallel Talk (\%) & 18.27 & 9.43 & 24.92 & 9.03 & 24.75 & 9.32 & 24.50 & 9.32 \\
Receptive Language & 1.15 & 2.10 & 15.01 & 10.33 & 28.97 & 14.81 & 40.27 & 15.80 \\
Expressive Language & 4.21 & 3.57 & 16.34 & 7.22 & 27.22 & 10.54 & 35.79 & 12.27 \\
Parent Utterances & 105.99 & 42.98 & 118.50 & 32.48 & 113.12 & 33.89 & 108.10 & 30.00 \\
Mean Length of Utterance & 2.94 & 1.22 & 3.07 & 0.69 & 3.28 & 0.80 & 3.55 & 0.83 \\
\hline
\end{tabular}


strategy (e.g., imitation, close-ended question) as well as composite scores used in the subsequent analyses (lower-level strategies, higher-level strategies). The most frequently used lower-level strategies across time were directives, comments, and close -ended questions. The most frequently used higher-level strategies were parallel talk, open-ended questions, and recast. Overall, lower-level strategies were used more frequently than higher-level strategies during parent-child interactions.

\section{Preliminary Analyses}

Prior to testing the final models described below, several approaches were attempted to separate the facilitative language techniques rather than combining them. Confirmatory factor analyses were conducted, but the models did not converge. Parameters were set with previous values from exploratory factor analyses and start values were also set, but these models still did not converge. It was suspected that the low variability of specific parent language techniques (i.e., expansion) may have affected the ability of these models to converge. However, the low variability of these techniques was expected due to the children's age and language impairment. As a result, composite scores of lower-level and higher-level strategies were created. As previously noted, these lower and higher-level strategies have been based on theory and research by speech and language pathologists. Use of the composite scores assigned in the final models improved model convergence and estimation, as well as interpretability of the results.

\section{Task Differences}

Data was obtained for this study by coding two five-minute video-taped parentchild interactions: Free Play and Art Gallery. Prior to using the composite scores of facilitative language techniques in the final analyses, task differences were examined 
using a series of $2 \times 4$ repeated measures analysis of variance (ANOVA). Task was the between-subjects variable, with two levels (Free Play and Art Gallery). Time was the within-subjects variable with four levels (pre-implantation, 12, 24, and 36 postimplantation). Descriptive statistics by task are presented in Table 5.

The first RM-ANOVA examined task differences for total utterances (number of words spoken by the parent). Results indicated a significant main effect for task $(F(1,128)=34.43, p<.001)$, with more utterances in Art Gallery when compared to Free Play (Figure 2). There was also a significant quadratic effect for time $(F(1,158)=28.98)$, $p<.001)$. Utterances increased from pre-implantation to 12 months post-implantation, but decreased at 24 and 36 months post-implantation.

A second RM-ANOVA was completed to examine task differences for MLU (Figure 3). There was a main effect for $\operatorname{task}(F(1,156)=9.22, p<.05)$, with longer MLUs in Art Gallery compared to Free Play. In addition, there was also a significant linear time effect $(F(1,156)=97.63, p<.001)$, with MLUs significantly increasing over three years implantation.

The third RM-ANOVA examined task differences in lower-level facilitative language techniques (Figure 4). No differences were found between the lower-level strategies in Art Gallery compared to Free Play $(F(1,159)=2.27, p>.05)$. However, results indicated that there was a significant time effect $(F(1,159)=412.35, p<.001)$. Lower-level facilitative language techniques decreased significantly three years postimplantation. No interaction between task and time was found.

Similar results were found for higher-level facilitative language techniques (Figure 5). No task differences were found for higher-level language techniques 
Table 5

Facilitative Language Techniques \& Parent Utterances by Task

\begin{tabular}{|c|c|c|c|c|c|c|c|c|}
\hline & \multicolumn{2}{|c|}{ Baseline } & \multicolumn{2}{|c|}{12 Month } & \multicolumn{2}{|c|}{24 Month } & \multicolumn{2}{|c|}{36 Month } \\
\hline & Free Play & Art Gallery & Free Play & Art Gallery & Free Play & Art Gallery & Free Play & Art Gallery \\
\hline & Mean $(S D)$ & Mean $(S D)$ & Mean $(S D)$ & Mean $(S D)$ & Mean $(S D)$ & Mean $(S D)$ & Mean $(S D)$ & Mean $(S D)$ \\
\hline Lower-Level Strategies (\%) & $74.75(13.41)$ & $75.26(11.18)$ & $60.86(13.66)$ & $62.73(12.91)$ & $56.40(13.77)$ & $56.08(13.68)$ & $48.07(13.88)$ & $53.18(14.80)$ \\
\hline Higher-Level Strategies (\%) & $24.92(12.32)$ & $23.74(11.24)$ & $38.94(13.62)$ & $36.94(13.14)$ & $43.38(14.02)$ & $43.68(13.73)$ & $51.85(14.46)$ & $46.52(14.60)$ \\
\hline Parent Utterances & $93.41(44.62)$ & $118.58(37.48)$ & $107.06(34.61)$ & $129.95(25.67)$ & $102.52(33.71)$ & $123.60(30.83)$ & $97.69(29.53)$ & $118.50(26.80)$ \\
\hline Mean Length of Utterance & $2.64(0.66)$ & $3.23(1.54)$ & $2.96(0.61)$ & $3.19(0.75)$ & $3.21(0.73)$ & $3.35(0.87)$ & $3.49(0.73)$ & $3.62(0.91)$ \\
\hline
\end{tabular}




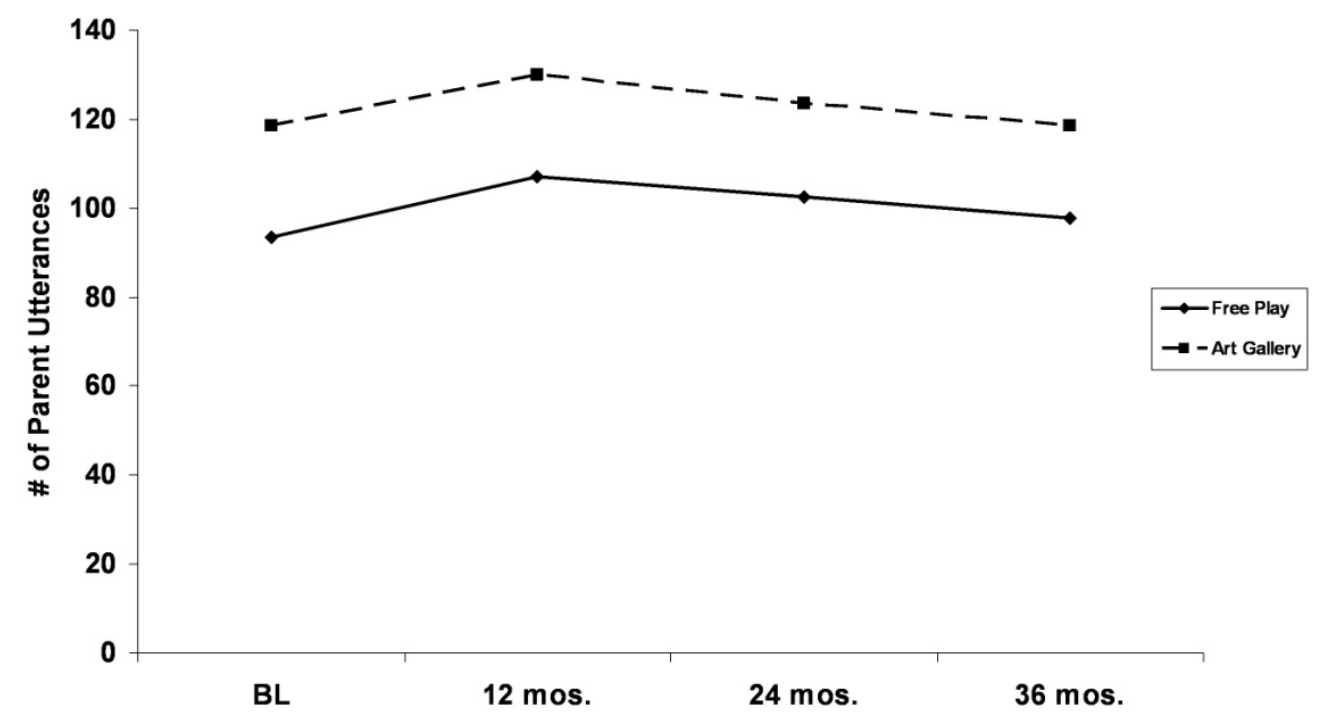

Figure 2. Repeated-measures analysis of variance of total number of parent utterances by task (Free Play versus Art Gallery) over three years post-implantation. Significant differences were found by task, with more parent utterances during Art Gallery. There was also a significant quadratic time effect; utterances increased from BL to 12 months post-implantation, but decreased at 24 and 36 months post-implantation.

$\mathrm{BL}=$ Baseline (prior to implantation) 


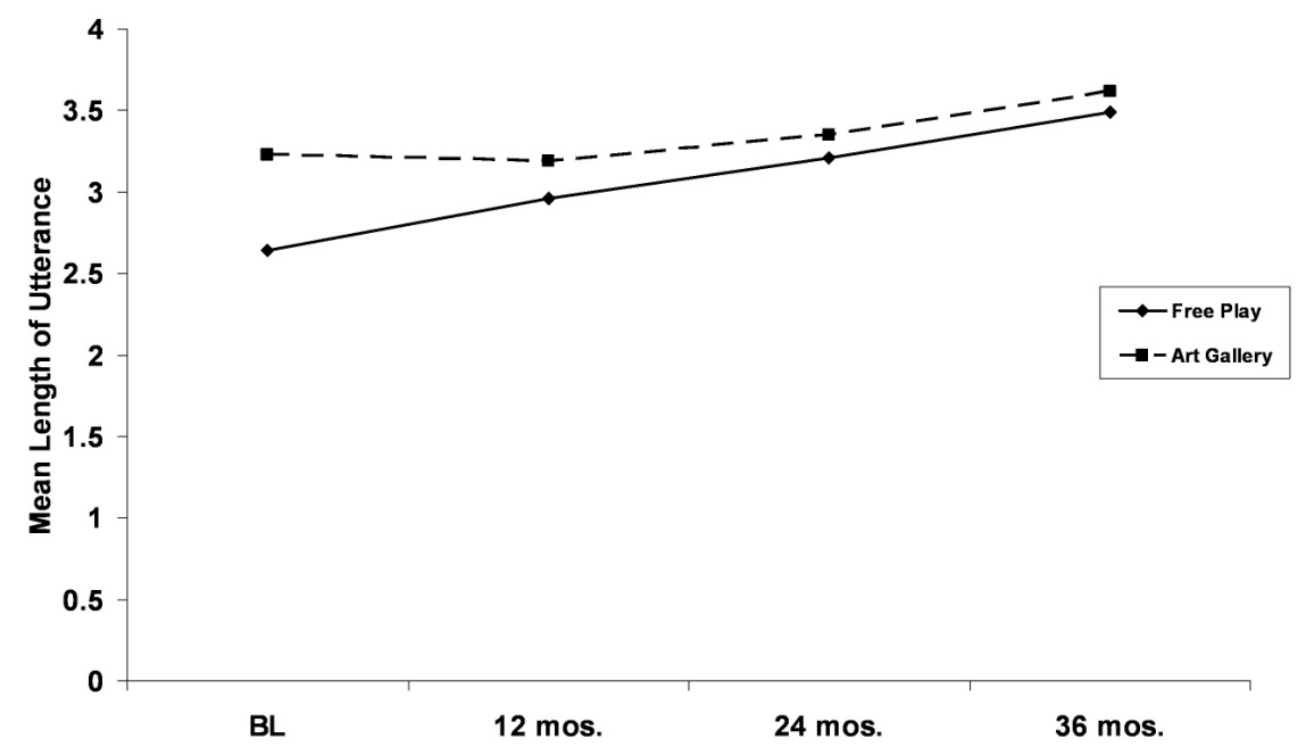

Figure 3. Repeated-measures analysis of variance of mean length of parent utterances by task (Free Play versus Art Gallery) over three years post-implantation. Significant differences were found by task, with longer parent utterances during Art Gallery. There was also a significant time effect; MLU increased significantly over time. $\mathrm{BL}=$ Baseline (prior to implantation) 


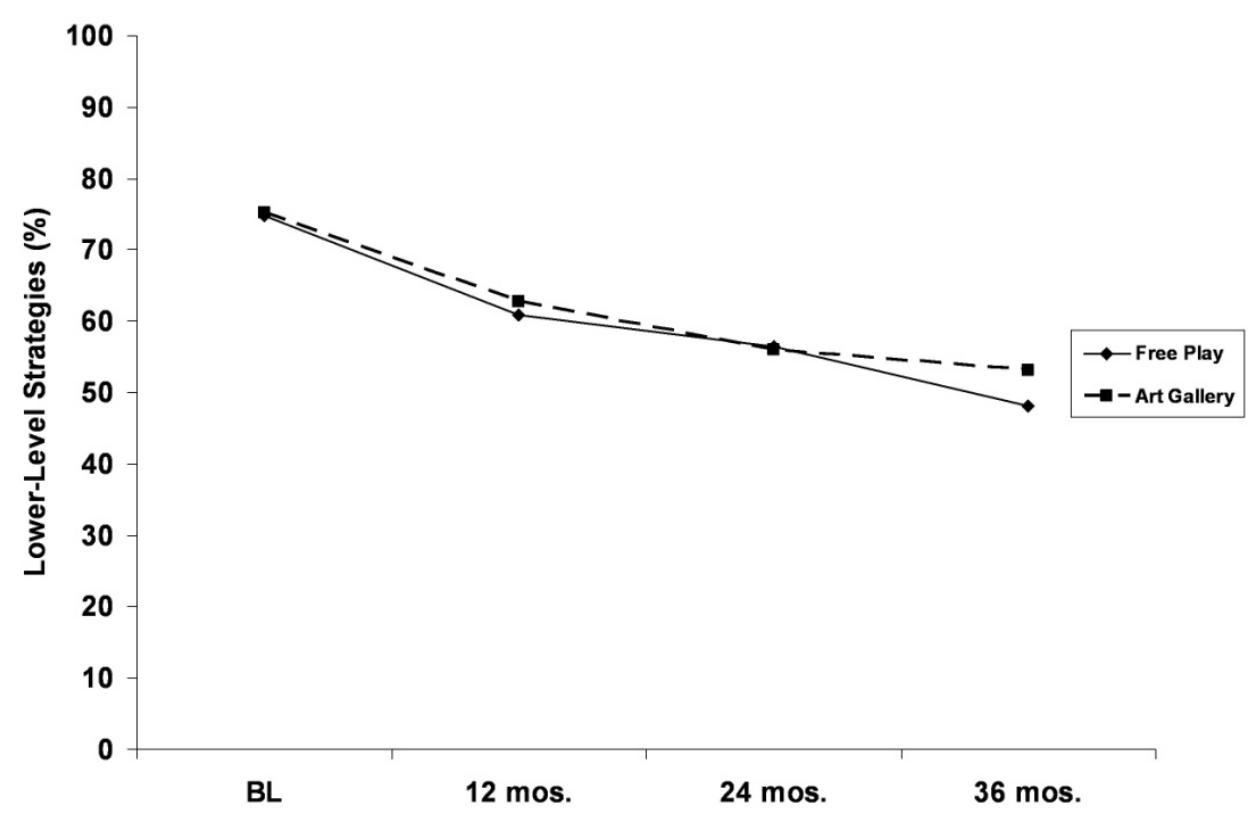

Figure 4. Repeated-measures analysis of variance of lower-level facilitative language techniques by task (Free Play versus Art Gallery) over three years post-implantation. No significant differences were found by task. A time effect was found; lower-level strategies decreased significantly over time.

$\mathrm{BL}=$ Baseline (prior to implantation) 


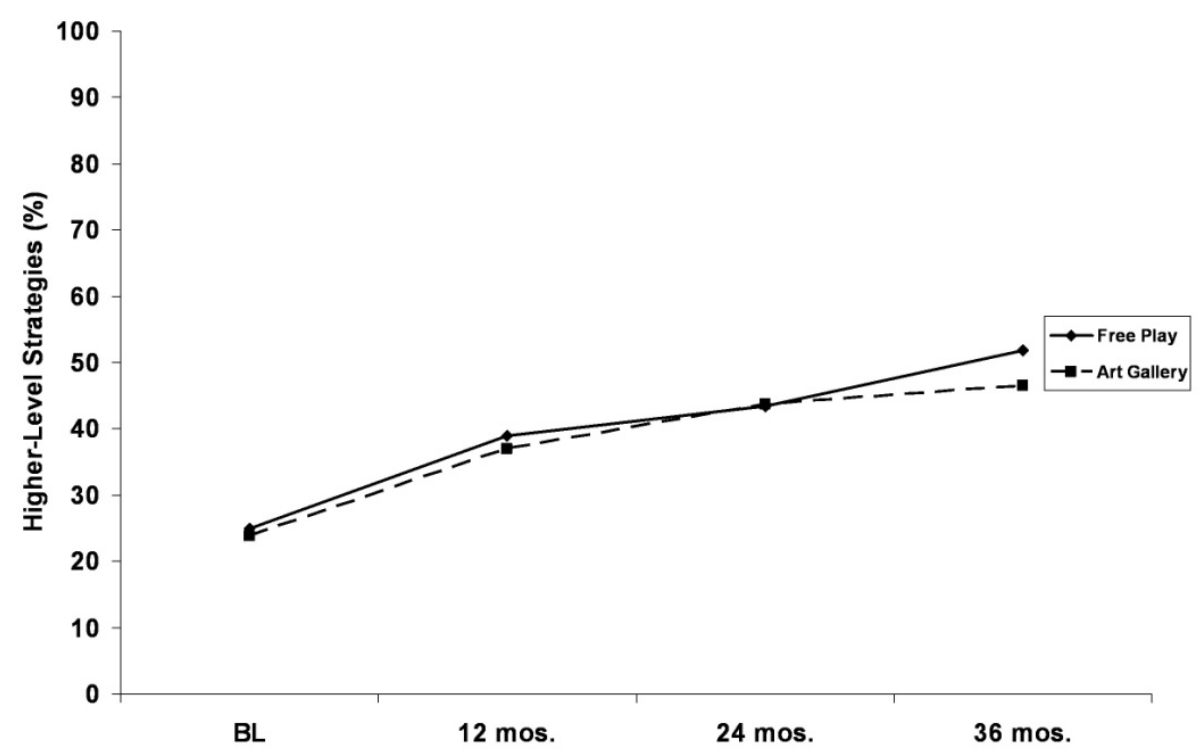

Figure 5. Repeated-measures analysis of variance of higher-level facilitative language techniques by task (Free Play versus Art Gallery) over three years post-implantation. No significant differences were by task. A time effect was found; higher-level strategies increased significantly over time.

$\mathrm{BL}=$ Baseline (prior to implantation) 
$(F(1,159)=2.55, p>.05)$. However, there was a significant time effect $(F(1,159)=$ $422.56, p<.001)$, with higher-level strategies increasing over three years implantation. No interaction between task and time was found. As a result, the composite scores for facilitative language techniques were used for all subsequent analyses.

In summary, differences in utterances and MLU were found when comparing Free Play and Art Gallery. Results were consistent with the expectation that structured tasks, such as Art Gallery would be better facilitators of oral communication between parents and children. However, no differences by task were found on the use of facilitative language techniques, including both lower-level and higher-level strategies. This suggested that although Art Gallery produces more communication between parents and children, the quality of the parent-child communication is similar in an unstructured compared to a structured task.

\section{Stage 1: Univariate Latent Growth Curve Modeling}

The first set of models was used to determine whether facilitative language techniques (lower and higher-level strategies) and language (expressive and receptive) significantly changed over three year's post-implantation. Figures 6-9 display path diagrams of the latent growth curve models, which estimated the level of both preimplantation (performance at baseline) and the latent growth variable (how children change). Loadings on the factors were constrained so that each child's trajectory would form a straight line (McArdle \& Nesselroade, 2002).

Facilitative Language Techniques. Both lower and higher-level facilitative language techniques showed significant change across three years post-implantation: fit indices for Lower-Level Strategies, loglikelihood $=-1304.39, \mathrm{df}=8, \mathrm{AIC}=2620.78$, 

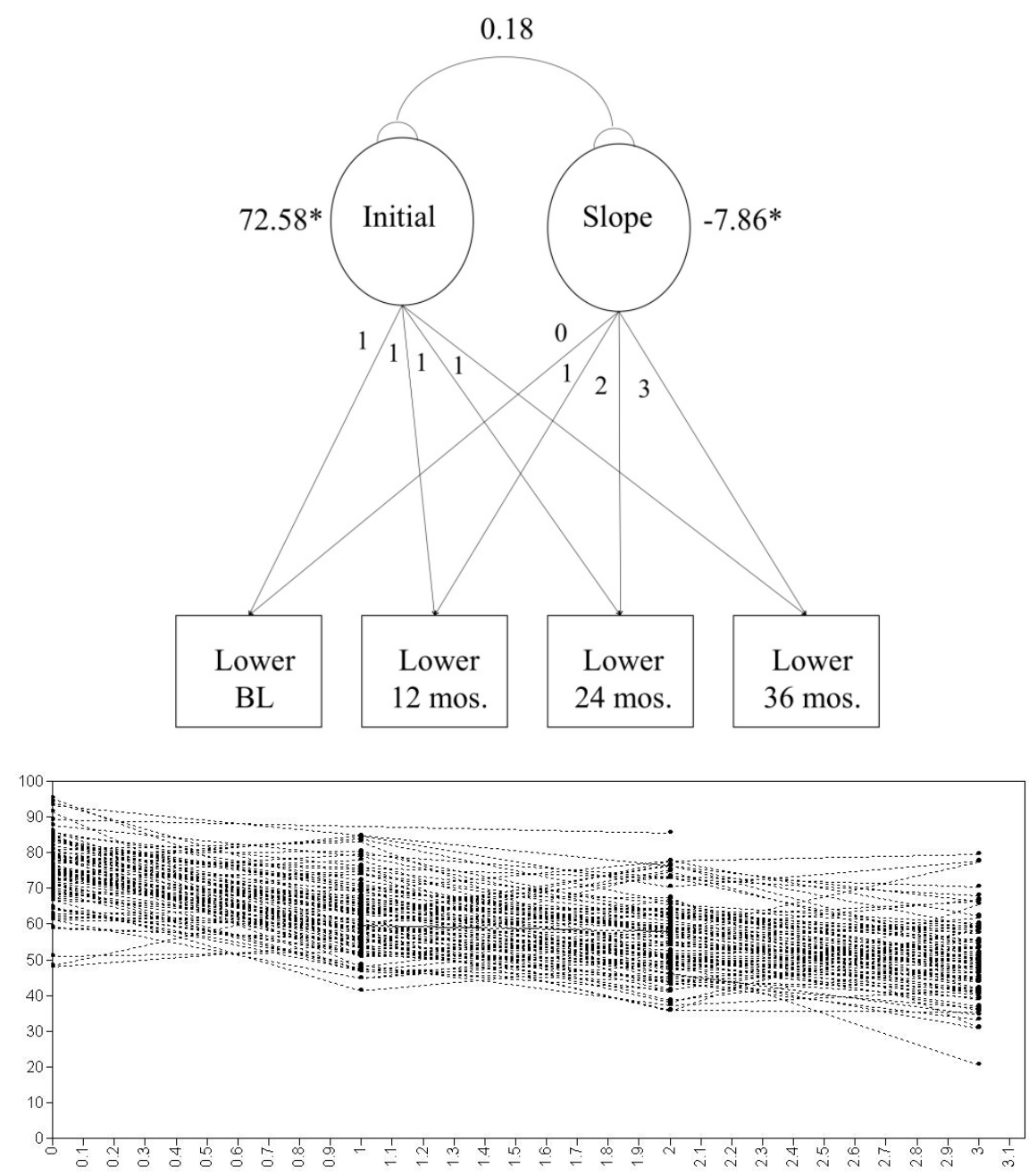

Figure 6. Predicted individual trajectories and latent growth curve models for lower-level facilitative language techniques. Top panel: Factor loadings in the model were set so that linear trajectories were predicted. Initial refers to the initial baseline (prior to implantation) level of the variable. Bottom panel: Lines reflect each person's predicted linear trajectory of change in lower-level strategies over three years post-implantation. $* p<.05$ 

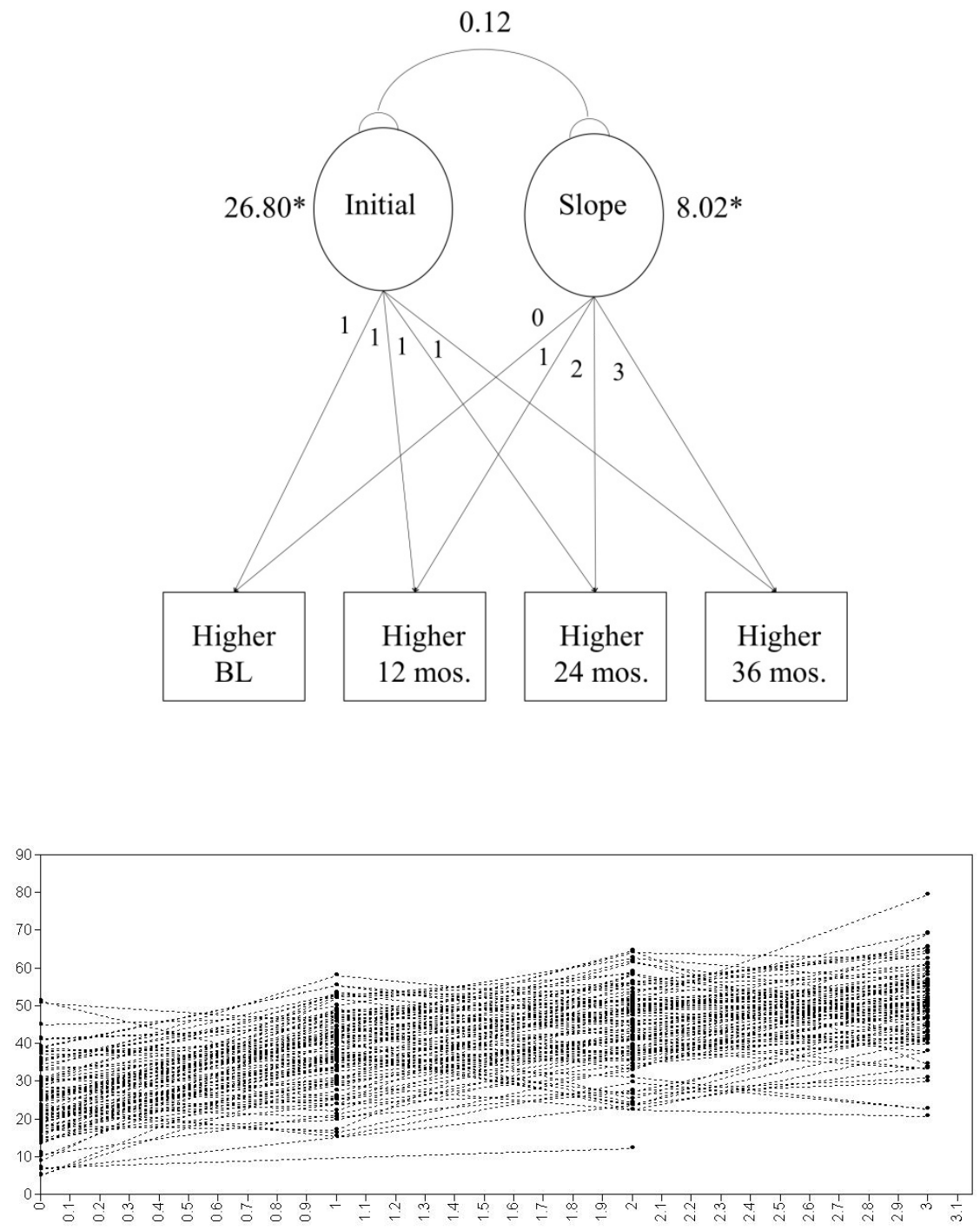

Figure 7. Predicted individual trajectories and latent growth curve models for higherlevel facilitative language techniques. Top panel: Factor loadings in the model were set so that linear trajectories were predicted. Initial refers to the initial baseline (prior to implantation) level of the variable. Bottom panel: Lines reflect each person's predicted linear trajectory of change in higher-level strategies over three years post-implantation. $* p<.05$ 

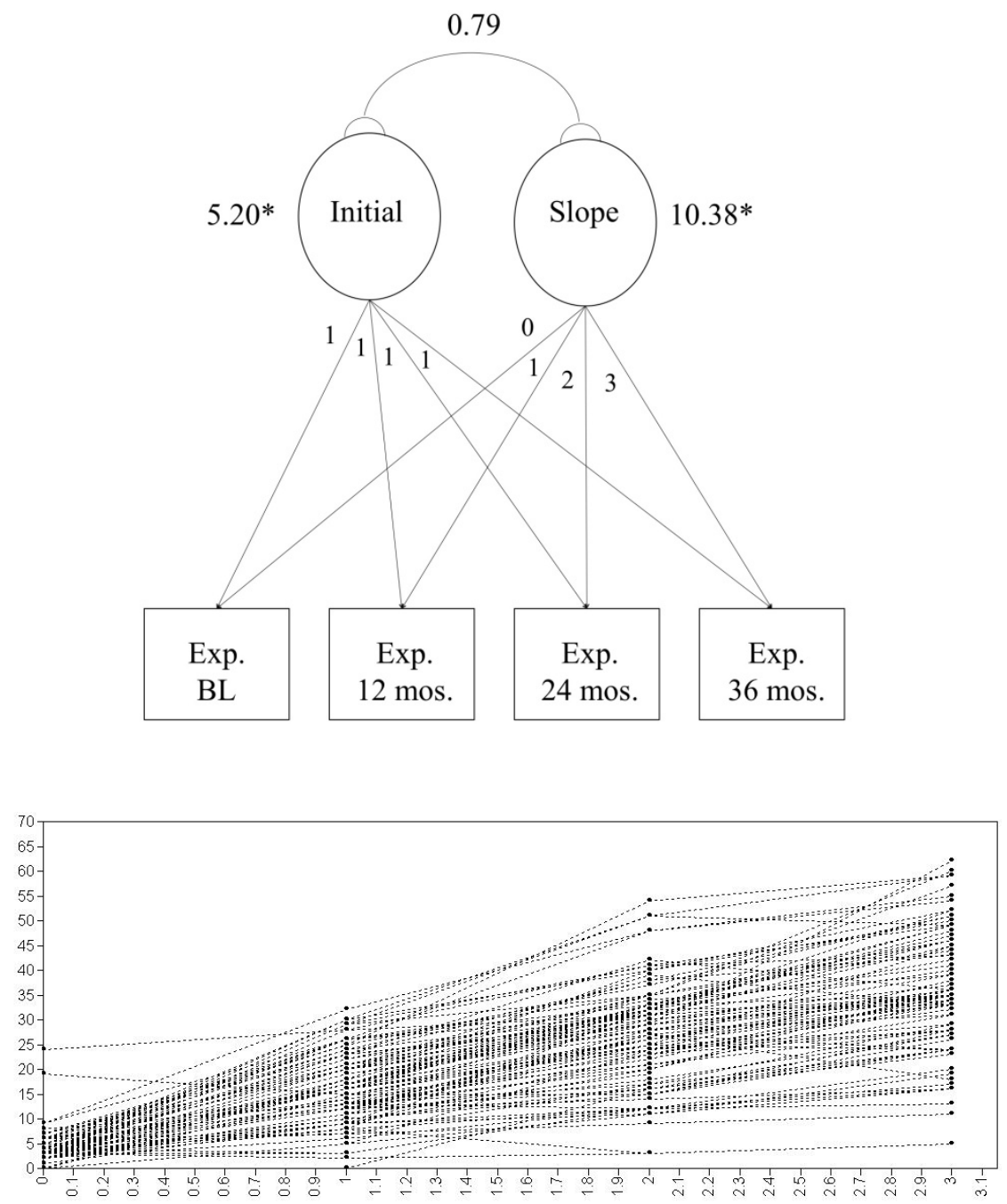

Figure 8. Predicted individual trajectories and latent growth curve models for expressive language based on the Reynell Developmental Language Scales. Top panel: Factor loadings in the model were set so that linear trajectories were predicted. Initial refers to the initial baseline (prior to implantation) level of the variable. Bottom panel: Lines reflect each person's predicted linear trajectory of change in expressive language over three years post-implantation.

$* p<.05$ 

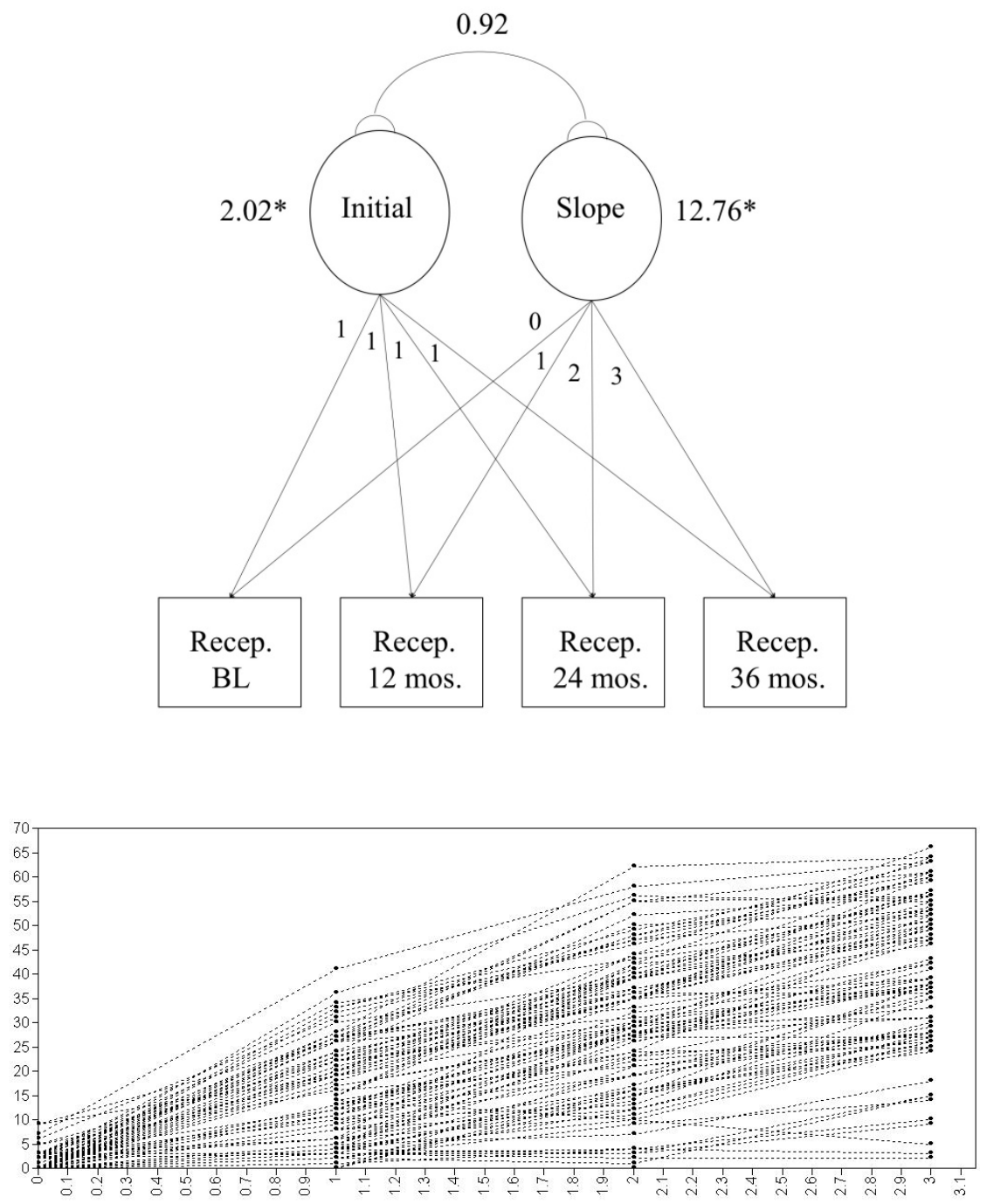

Figure 9. Predicted individual trajectories and latent growth curve models for receptive language based on the Reynell Developmental Language Scales. Top panel: Factor loadings in the model were set so that linear trajectories were predicted. Initial refers to the initial baseline (prior to implantation) level of the variable. Bottom panel: Lines reflect each person's predicted linear trajectory of change in receptive language over three years post-implantation.

$* \mathrm{p}<.05$ 
$\mathrm{BIC}=2635.91, \mathrm{RSMEA}=0.14$; fit indices for Higher-Level Strategies, loglikelihood $=$ $-307.20, \mathrm{df}=8, \mathrm{AIC}=2626.40, \mathrm{BIC}=2641.53, \mathrm{RSMEA}=0.15$. Estimates of lowerlevel language techniques began on average at $72.58 \%$ of the total 10 minute interaction and decreased by $7.86 \%(p<.001)$ over time. Estimates of higher-level language techniques were on average, $26.80 \%$ of the total and increased by $8.02 \%$ over time $(p<.001)$. Thus, both lower and higher-level strategies displayed significant change over time, with lower-level strategies decreasing and higher-level strategies increasing over time.

Language. Similar to these results for facilitative language techniques, both expressive and receptive language scores showed significant change across three years post-implantation: fit indices for expressive language, $\log$ likelihood $=-1082.63, \mathrm{df}=8$, $\mathrm{AIC}=2177.25, \mathrm{BIC}=2192.31, \mathrm{RMSEA}=0.23$; fit indices for receptive language loglikelihood $=-1151.47, \mathrm{df}=8, \mathrm{AIC}=2314.93, \mathrm{BIC}=2330.00, \mathrm{RMSEA}=0.40$. Estimates of expressive language raw scores were, on average, 5.20 and increased by 10.38 points $(p<.001)$ over time. Estimates of receptive language raw scores were on average 2.02 and increased by 12.76 points $(p<.001)$ over time. Thus, both expressive and receptive language scores demonstrated significant improvement over three years of implantation.

\section{Stage 2: Dual Latent Growth Curve Modeling}

The next set of models investigated whether changes in facilitative language techniques and language scores were related to each other. Univariate latent growth curve models were run simultaneously and the correlation of one variable's latent change with the other variable's latent change was estimated. 
Lower-Level Strategies. As noted in Figure 10, the latent change on lower-level strategies was significantly correlated with latent change on expressive language $(r=0.41$, $p<.01$; fit indices loglikelihood $=-2374.50, \mathrm{df}=34, \mathrm{AIC}=4769.00, \mathrm{BIC}=4794.22$, RMSEA = 0.16). In addition, baseline (pre-transplant) facilitative language techniques and expressive language scores were predictors of this change process (see Figure 10). The latent change on lower-level strategies was also significantly correlated with latent change on receptive language (see Figure $11 ; r=0.47, p<.01$; fit indices loglikelihood = 2444.79, $\mathrm{df}=34, \mathrm{AIC}=4909.58, \mathrm{BIC}=4934.79, \mathrm{RMSEA}=0.223)$. Initial facilitative language techniques and receptive language scores were also predictors of this change process.

Higher-Level Strategies. Similar results were found for higher-level strategies (see Figures 12 and 13). The latent change on higher-level strategies was significantly correlated with latent change on expressive and receptive language scores (Expressive: $r$ $=0.41, p<.01$; fit indices loglikelihood $=-376.66, \mathrm{df}=34, \mathrm{AIC}=4773.33, \mathrm{BIC}=$ 4798.54, RMSEA = 0.17; Receptive: $r=0.47, p<.01$; fit indices loglikelihood $=-$ 2446.61, $\mathrm{df}=34, \mathrm{AIC}=4913.21, \mathrm{BIC}=4938.43, \mathrm{RMSEA}=0.23$, respectively). Furthermore, initial higher-level language techniques and expressive and receptive language scores were significant predictors of this change in language.

In summary, as hypothesized, changes in facilitative language techniques and measured language were related to one another. Specifically, lower-level strategies were negatively related to improvements in expressive and receptive language. In contrast, as predicted, higher-level strategies were positively related to improvements in expressive and receptive language. 


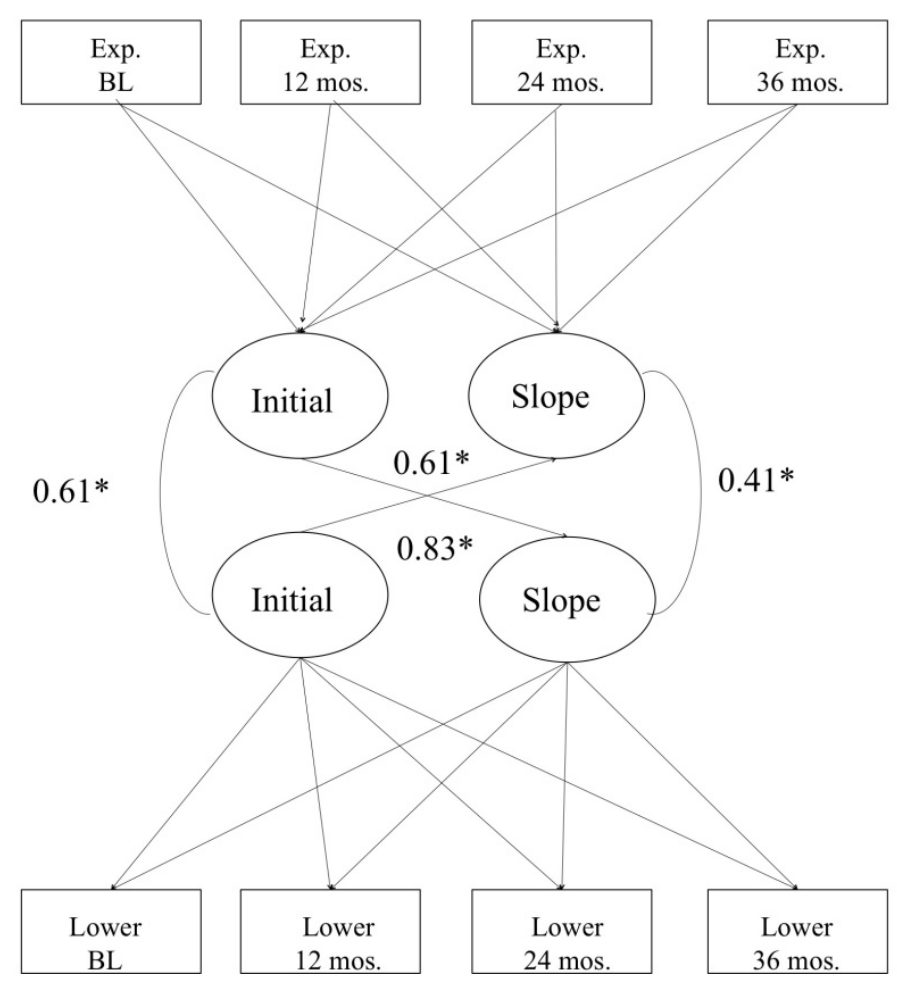

Figure 10. Dual latent growth curve models of lower-level facilitative language techniques and expressive language modeled simultaneously and indicating that the slopes of the two change processes are correlated. Initial refers to the initial baseline (prior to implantation) level of the variable. 


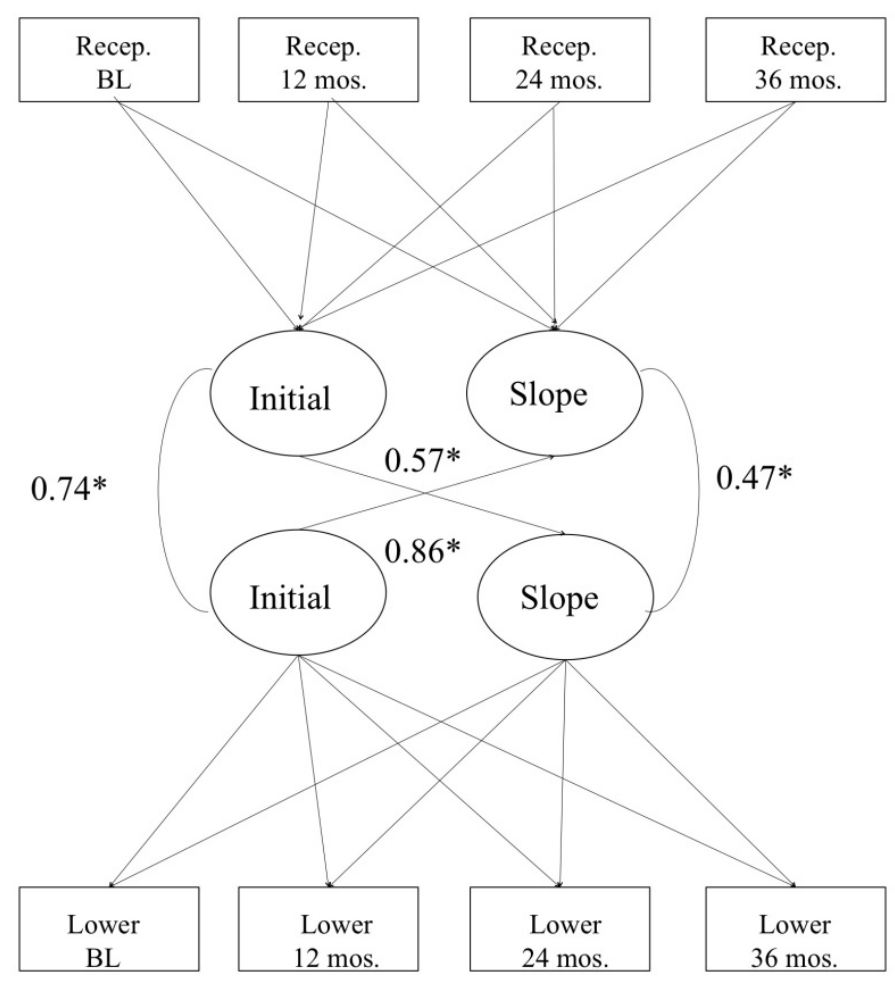

Figure 11. Dual latent growth curve models of lower-level facilitative language techniques and receptive language modeled simultaneously and indicating that the slopes of the two change processes are correlated. Initial refers to the initial baseline (prior to implantation) level of the variable. 


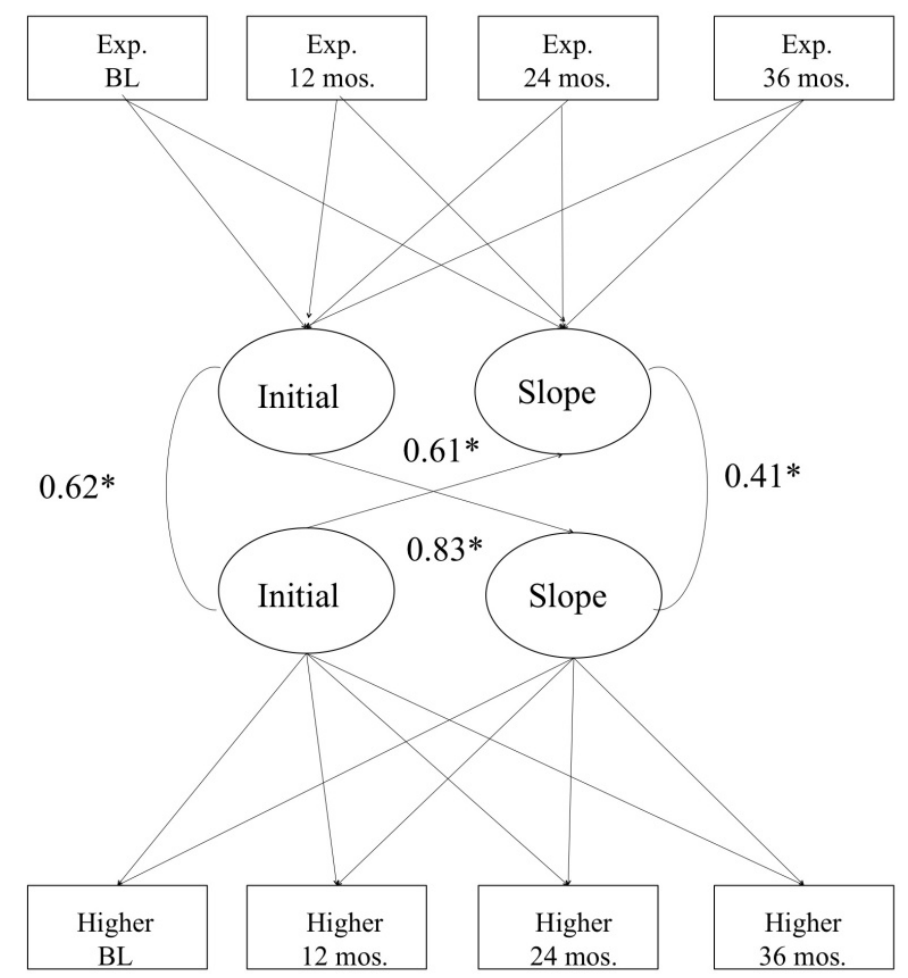

Figure 12. Dual latent growth curve models of higher-level facilitative language techniques and expressive language modeled simultaneously and indicating that the slopes of the two change processes are correlated. Initial refers to the initial baseline (prior to implantation) level of the variable. 


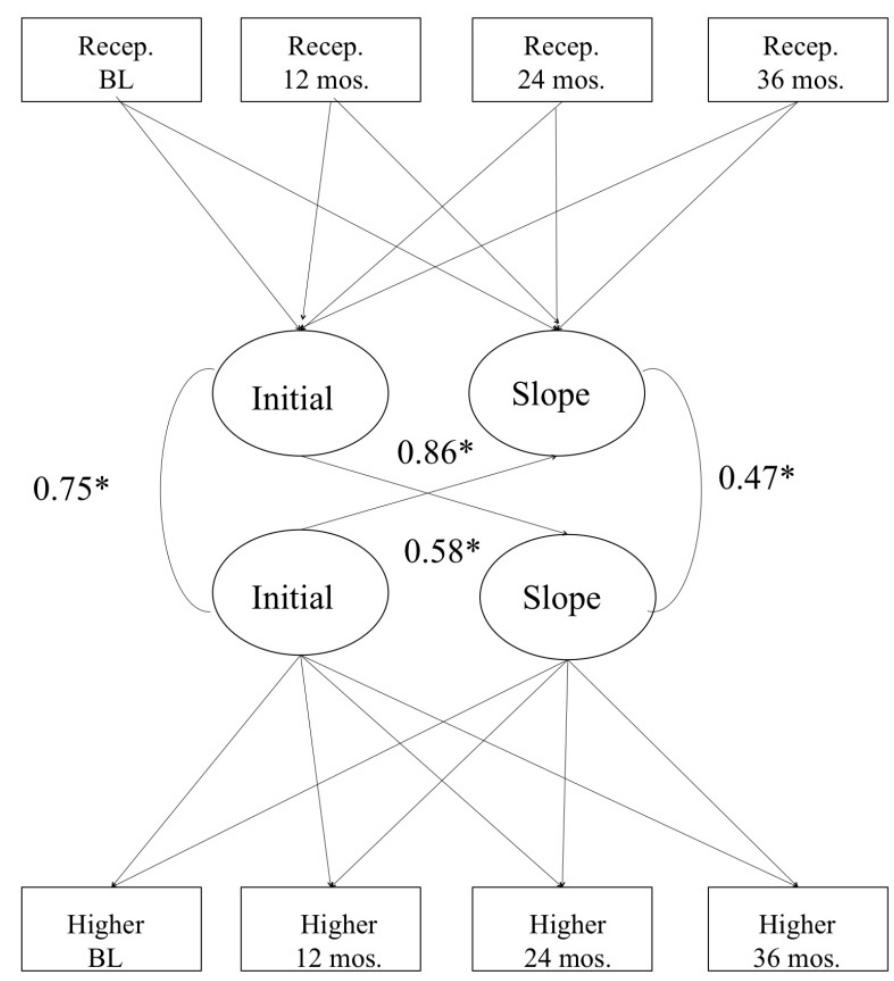

Figure 13. Dual latent growth curve models of higher-level facilitative language techniques and receptive language modeled simultaneously and indicating that the slopes of the two change processes are correlated. Initial refers to the initial baseline (prior to implantation) level of the variable. 


\section{Stage 3: Dynamic Bivariate Latent Difference Score Modeling}

Bivariate LDS modeling provides a flexible framework for testing one variable as a predictor of change in another. Thus, it allows the evaluation of predictive relationships in a multivariate change process. It facilitates modeling the relationship in the opposite direction, to evaluate whether change is uni- or bidirectional. In this model, many parameters were constrained; specifically, all of the unlabeled arrows to 1 were constrained. Only one alpha ( $\alpha$; to model straight-line growth) and gamma ( $\gamma$; to model change process over time) were estimated for all time points (see McArdle \& Hamagami, 2001 , for a detailed explanation of these procedures). The goal was to test specific hypotheses about which change process (facilitative language techniques or language) was a leading indicator of the other. Thus, growth was constrained to be linear and the number of parameters estimated were limited in each model, allowing it to converge fairly easily.

Model 1: Lower-Level Language Techniques and Expressive Language. Model 1 attempted to determine whether lower-level strategies predicted later change in expressive language scores. Figure 14 presents a diagram showing this relationship with the bivariate LDS model (fit indices: Loglikelihood $=-2334.91, \mathrm{df}=28, \mathrm{AIC}=4719.81$, $\mathrm{BIC}=4782.86, \mathrm{RMSEA}=0.10)$. As a reminder, the arrows labeled with $\gamma($ gamma $)$ predicted the relationship between variables. Lower-level strategies did not significantly predict improvements in expressive language over three years of implantation. Specifically, lower-level facilitative language techniques did not predict change in expressive language at 12 months $(t=1.84, p>.05), 24$ months $(t=1.83, p>.05)$, or 36 months post-implantation $(t=1.91, p>.05)$. Similarly, expressive language scores did not 


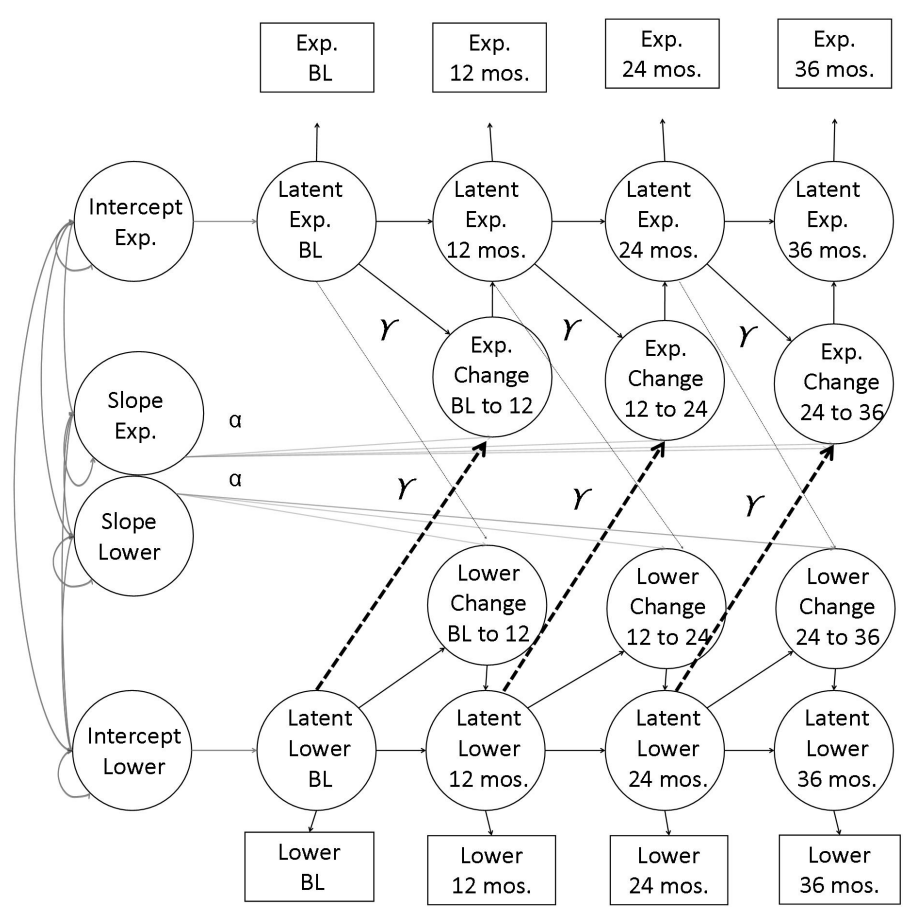

Figure 14. Bivariate latent difference score model of lower-level language techniques and expressive language. Lower-level strategies did not significantly predict change in expressive language over time. Expressive language scores also did not predict change in lower-level strategies. $\mathrm{BL}=$ baseline assessment (prior to cochlear implantation); mos. = months post-implantation; $\alpha=$ estimate to model straight-line growth; $\gamma=$ estimate to model change process across time. 
predict change in lower-level strategies at 12 months $(t=1.61, p>.05), 24$ months $(=1.00$, $p>.05)$, or 36 months post-implantation $(t=0.89, p>.05)$.

Model 2: Lower-Level Language Techniques and Receptive Language. Similar to Model 1, Model 2 attempted to determine whether lower-level strategies predicted change in receptive language. Figure 15 shows the relationship with the bivariate LDS model (fit indices: Loglikelihood $=-2364.51, \mathrm{df}=28, \mathrm{AIC}=4779.03, \mathrm{BIC}=4842.07$, RMSEA = .09). As expected, lower-level strategies did not predict improvements in receptive language. Rather, there was the inverse relationship; a decrease in lower-level strategies predicted improvements in receptive language scores at 12 months $(t=-2.20$, $p<.05), 24$ months $(t=-2.12, p<.05)$, and 36 months post-implantation $(t=-2.05, p<.05)$. Similar to Model 1, receptive language scores did not predict change in lower-level strategies at 12 months $(t=1.61, p>.05), 24$ months $(t=1.33, p>.05)$, or 36 months postimplantation $(t=0.07, p>.05)$.

Model 3: Higher-Level Language Techniques and Expressive Language. Model 3 attempted to determine whether higher-level strategies predicted change in expressive language scores. Figure 16 shows the relationship with the bivariate LDS model (fit indices: Loglikelihood $=-2325.04, \mathrm{df}=28, \mathrm{AIC}=4700.07, \mathrm{BIC}=4763.12, \mathrm{RMSEA}=$ .01). As hypothesized, higher-level strategies significantly predicted improvements in expressive language over time. Increases in higher-level strategies predicted improvements in expressive language at 12 months ( $t=2.59, p<.01), 24$ months $(t=2.45$, $p<.05)$, and 36 months post-implantation $(t=2.37, p<.05)$. Similar to the previous model, expressive language scores did not predict change in higher-level strategies (12 months $t=1.80, p>.05 ; 24$ months $t=0.90, p>.05 ; 36$ months $t=0.64, p>.05)$. 


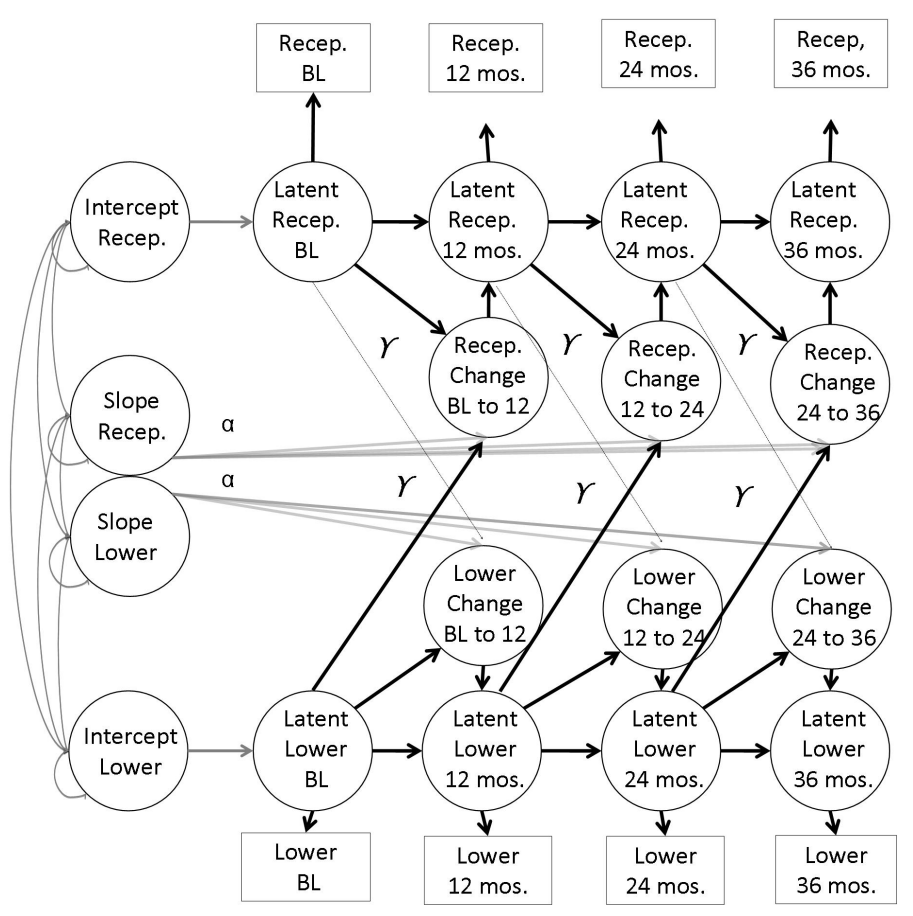

Figure 15. Bivariate latent difference score model of lower-level language techniques and receptive language. As lower-level strategies decreased, receptive language scores increased. Receptive language scores also did not predict change in lower-level strategies. $\mathrm{BL}=$ baseline assessment (prior to cochlear implantation); mos. = months post-implantation; $\alpha=$ estimate to model straight-line growth; $\gamma=$ estimate to model change process across time. 


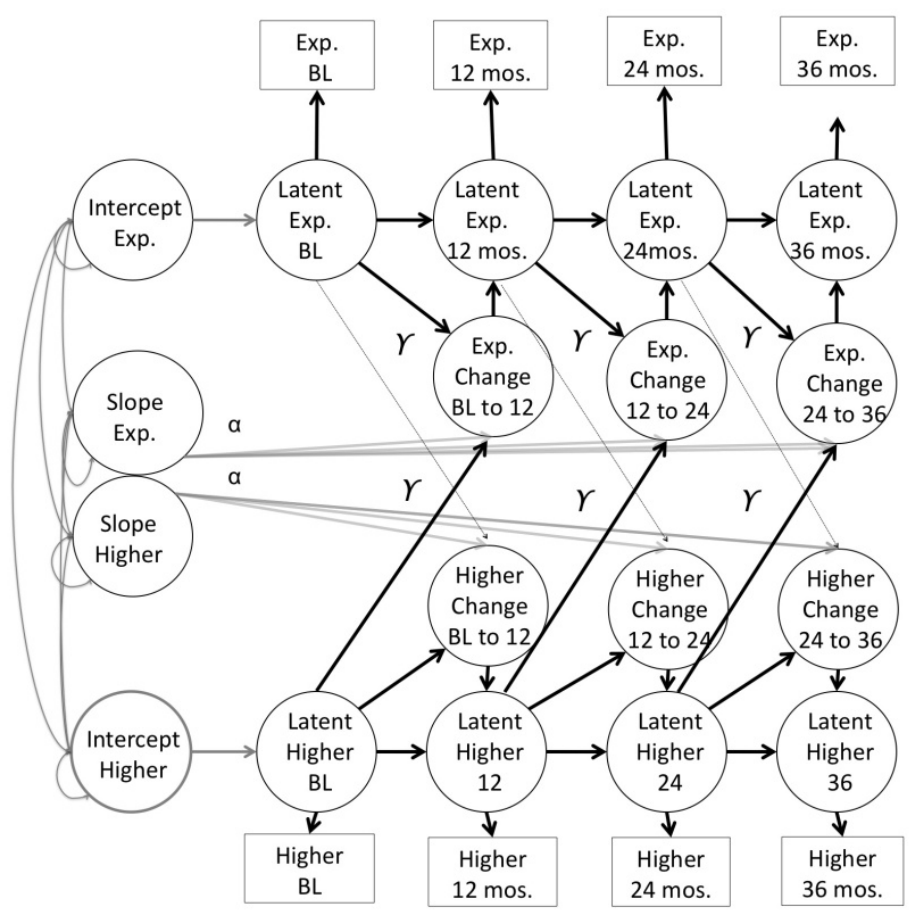

Figure 16. Bivariate latent difference score model of higher-level language techniques and expressive language. Higher-level strategies predicted improvements in expressive language scores over time. Expressive language scores did not predict change in higherlevel strategies. $\mathrm{BL}=$ baseline assessment (prior to cochlear implantation); mos. = months post-implantation; $\alpha=$ estimate to model straight-line growth; $\gamma=$ estimate to model change process across time. 
Model 4: Higher-Level Language Techniques and Receptive Language. Model

4 attempted to determine whether higher-level strategies predicted change in receptive language. Figure 17 shows the relationship with the bivariate LDS model (fit indices:

Loglikelihood $=-2361.90, \mathrm{df}=28, \mathrm{AIC}=4773.79, \mathrm{BIC}=4836.83, \mathrm{RMSEA}=.07)$.

Higher-level strategies also predicted improvements in receptive language; however, the relationship was only significant at 36 months post-implantation. Higher-level strategies used at 24 months post-implantation significantly predicted change in receptive language at 36 months post-implantation $(t=1.96, p<.05)$. The relationship between higher-level strategies and change in receptive language trended toward significance at 12 months $(t=1.73, p<.08)$ and 24 months post-implantation $(t=1.87, p<.08)$. Thus, there appears to be a delayed effect of higher-level strategies on growth in receptive language scores. Similar to previous models, receptive language scores did not predict change in higherlevel strategies at 12 months $(t=-0.60, p>.05), 24$ months $(t=-1.14, p>.05)$, or 36 months post-implantation $(t=-0.20, p>.05)$. 


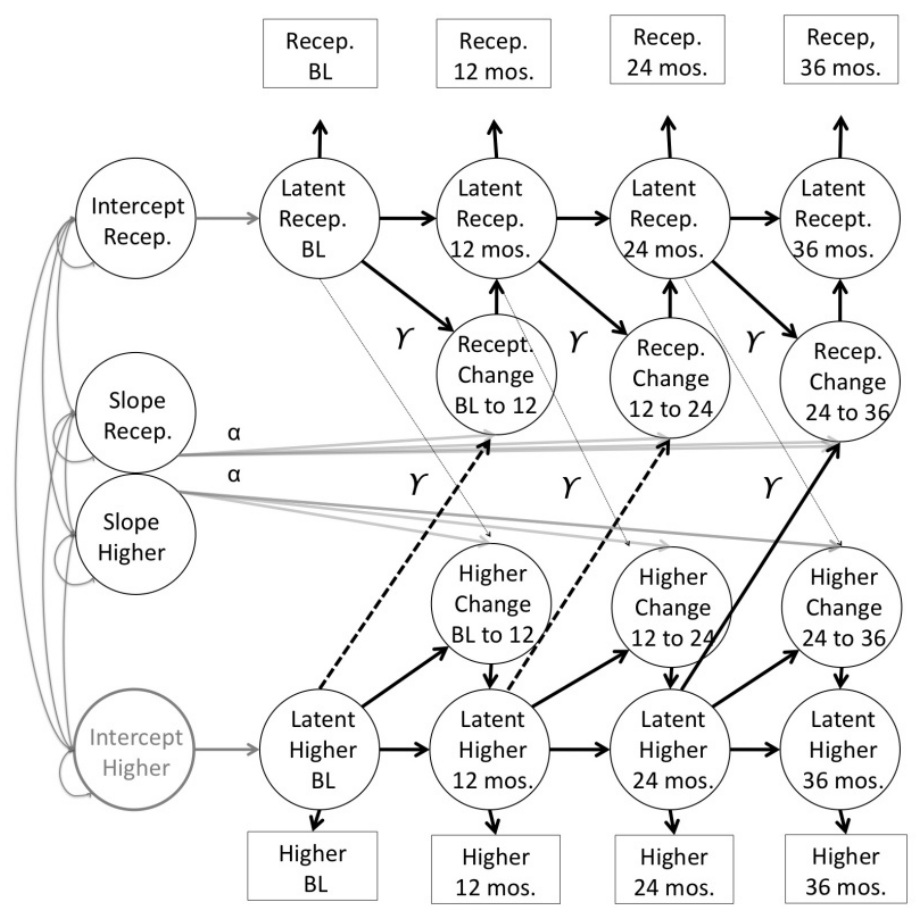

Figure 17. Bivariate latent difference score model of higher-level language techniques and receptive language. Higher-level strategies predicted improvements in receptive language at 36 months, but no significant relationship was found at 12 and 24 months post-implantation. Receptive language scores did not predict change in higher-level strategies. $\mathrm{BL}=$ baseline assessment (prior to cochlear implantation); mos. $=$ months post-implantation; $\alpha=$ estimate to model straight-line growth; $\gamma=$ estimate to model change process across time. 


\section{CHAPTER V}

\section{Discussion}

This study examined the effects of parents' facilitative language techniques on the growth of young, deaf children's language for 3 years following cochlear implantation. This sample was drawn from the largest, youngest, and most nationally representative sample of young deaf children receiving cochlear implants. The major purpose of the study was to identify which facilitative language techniques were most effective in fostering the development of expressive and receptive language in these children. Secondary aims included identifying the most frequent facilitative language techniques used by parents and comparing the types of facilitative language techniques used in a structured versus an unstructured task.

Moderate support was found for the hypothesis that higher-level language techniques would be associated with improvement in both expressive and receptive language across three years post-implantation. In contrast, lower-level strategies had either no effect or a negative effect on expressive and receptive language scores. In terms of secondary aims, findings showed that parents of children with cochlear implants used a combination of lower and higher-level strategies during video-taped parent-child interactions. Directives, comments, and close-ended questions were the most frequently used lower-level strategies and parallel talk, open-ended questions, and recast were the most frequently used higher-level strategies. Further, as hypothesized, parents used more higher than lower-level strategies across time. In terms of the differences between the structured Art Gallery task and unstructured Free Play task, more and longer utterances were observed in the structured compared to unstructured task. However, no differences 
were found in the use of facilitative language strategies. Lastly, to test the direction of these effects, bidirectional analyses indicated that language scores did not predict changes in the use of lower-level or higher-level strategies; parents' strategies were associated with growth in language.

The hypothesis that higher-level strategies would be significantly associated with growth of oral language was moderately supported. Higher-level strategies consistently predicted growth in expressive language at all assessment points. However, although higher-level strategies predicted significant changes in receptive language at 36 months post-implantation, only trends toward significance were found at 12 and 24 months postimplantation. Thus, it appeared that facilitative language techniques had a delayed effect on receptive language. This may be due to the context in which these language techniques are measured, since they heavily rely on the child's vocalizations. Parents' typically provide this linguistic input in response to the child's bid for communication, which may more strongly influence expressive rather than receptive language. For example, when the parent is utilizing parallel talk (i.e., a higher-level strategy), the child has multiple opportunities for verbal expression. In contrast, when the parent asks a close-ended question (i.e., a lower-level strategy), the child is likely to respond nonverbally (nodding “yes”) or with a single word. Thus, higher-level strategies may facilitate a dynamic communication interchange. This process appears to evolve over time where higher-level strategies and the child's verbal output create a self-reinforcing cycle that yields better growth of expressive language. This is supported by the 3 -year longitudinal data, which showed a consistent increase in the use of higher-level strategies. 
These results are consistent with prior studies of children with cochlear implants, which have reported that higher-level strategies, such as recast and open-ended questions, are positively associated with children's receptive and expressive language (DesJardin, Ambrose, \& Eisenberg, 2009; DesJardin \& Eisenberg, 2007). Furthermore, DesJardin and colleagues (2009) also found a negative relationship between lower-level strategies, such as linguistic mapping and directives, and receptive and expressive language skills (DesJardin \& Eisenberg, 2007). Lower-level strategies are recommended for children at the single-word stage of language development, while higher-level strategies provide support for children performing at the two-to-three word level. Further research is needed to determine when and for how long lower-level language techniques should be used with deaf children using cochlear implants before they begin to have a negative effect on children's language growth.

These results also strongly supported the hypothesis that over time, parents would increase their use of higher-level communication strategies in their dyadic interactions. Over the 3 years of measurement, higher-level strategies increased significantly from $25 \%$ to $50 \%$, while lower-level strategies decreased significantly from $75 \%$ to $50 \%$. To date, only two studies have investigated facilitative language techniques in deaf children with cochlear implants and only one study used a longitudinal design. In the longitudinal study, which assessed phonological awareness and reading skills, results showed that higher-level facilitative language techniques positively contributed to children's literacy (DesJardin, Ambrose, \& Eisenberg, 2008). However, neither study reported descriptive information about the amount of time parents' spent using these strategies. In addition, these studies consisted of small sample sizes and data collected at a single implant center. 
Thus, this was the first study to systematically measure these dyadic interactions and quantify the intensity of parental language input in a large nationally representative sample.

As expected, the structured Art Gallery task was more effective in fostering communication than the unstructured Free Play task. Parents' had significantly more and longer utterances in the Art Gallery versus Free Play tasks. These results are supported by prior studies using this task with children with atypical language development (Deckner, Adamson, \& Bakeman, 2003). However, differences in the frequency of various types of facilitative language techniques were not found. These results have important clinical implications because parental linguistic input, such as vocabulary diversity and MLU, have been shown to correlate positively with language scores and later school achievement (DesJardin \& Eisenberg, 2007; Koester, Papousek, \& Smith-Gray, 2000; Weizman \& Snow, 2001). In addition, previous literature has suggested that mothers' MLU accounts for most of the variance in children's expressive and receptive language skills (Griolametto et al., 1999; Murray, Johnson, \& Peters, 1990). Thus, the Art Gallery task may be optimal for both assessing the quality of parental language input and for teaching parents how to facilitate their child's communication.

Further, although this study could not determine cause and effect, analyses were conducted to test bidirectional effects. Specifically, analyses examined whether children's expressive language skills led to increases in parents' use of higher-level communication strategies. No support was found for this relationship. Children's expressive and receptive language skills were not associated with changes in parental language strategies over time. Thus, within the limits of this study design, it appears that 
parents' language techniques had a unidirectional effect on children's language development.

\section{Limitations of this Study}

First, although strong evidence was found that parents' use of higher-level language strategies increased children's language skills over time, it is not possible to conclude that this association was causal. This would require randomization to different levels of parental language input, which was not possible given the study design and goal of study to identify specific language techniques used naturally by parents during their interactions with their children. Future studies should test the effects of these language strategies in a randomized, controlled trial. Second, the sample was limited to deaf children ages 2 and younger receiving cochlear implants. Thus, it is not known whether these facilitative language strategies would continue to be effective in promoting expressive and receptive language skills in children implanted after the age of 2. Finally, in the first year of the study, many children had severely limited language and thus, variability in their language scores was limited. A simpler language measure, such as the MacArthur-Bates Communicative Development Inventory, might have been more sensitive to changes in language early in the study.

\section{Clinical Implications/Future Directions}

These results have several clinical implications. These findings demonstrated that parents have the potential to facilitate their child's language development, which may also have positive effects on school performance and social skills post-cochlear implantation. This information may serve as a guide for cochlear implant programs seeking to provide further assistance and care to children who are not developing 
adequate language after cochlear implantation. In addition, the strategies can also be used by both parents and teachers to facilitate optimal use of the auditory information provided by the implant.

Future studies should examine the effectiveness of these strategies on children implanted after 2 years of age. It is likely, based on DesJardin and colleagues (2009) that these parent strategies will continue to foster growth in language for older children. Studies should also begin to design interventions for parents using a coaching model where parents receive hands-on training and practice using these effective facilitative language techniques. This intervention should then be evaluated in a randomized controlled trial.

This intervention may also be incorporated into early intervention programs. Currently, the federal government has recognized that having a child with a disability presents significant challenges for the family. Thus, the government has enacted the Individuals with Disabilities Education Improvement Act (IDEIA, 2004) and the Division of Early Childhood (DEC) Recommended Practices in Early Intervention/Early Childhood Special Education (Sandall, Hemmeter, Smith, \& McLean, 2005), which supports the notion that parents and other key family members play an active role in children's learning and development. There are several parts to this act which are relevant to hearing impaired children: Part C (birth to 3 years old) and Part B (3-5 years old; DesJardin, 2009). Under Part C, families and children with a known disability or families and children at-risk for future learning deficits receive free early intervention services. Families also receive an Individual Family Service Plan (IFSP), which is developed and executed for the family and the child, with services delivered in the home environment 
(Walsh, Rous, \& Lutzer, 2000). This would be an ideal environment to train parents on these facilitative language techniques through Part $\mathrm{C}$ of the IDEIA.

Furthermore, if further studies find that these facilitative language techniques are effective for children implanted after 2 years of age, this intervention may also be applied under Part B of the IDEIA. Part B encourages parental involvement in intervention for preschool and school-aged children. However, parents do not necessarily receive direct services under this provision (Guralnick, 2005). Thus, parents would need to learn the higher-level facilitative language techniques early on, during Part C, and continue to use the strategies as their children develop. Taken together, early intervention programs, which provide professional guidance to parents, may have a significant impact on the language development of children with hearing impairments, as well as high quality parent-child relationships and positive long-term educational and social outcomes. 


\section{REFERENCES}

Abidin, R.R. (1983). Parenting Stress Index (PSI)-Manual and administration booklet. Charlottesville, VA: Pediatric Psychology Press.

Bakeman, R., \& Adamson, L. (1984). Coordinating attention in people and objects in mother-infant and peer-infant interaction. Child Development, 55, 1278-1289.

Baldassari, C.M., Schmidt, C.S., Schubert, C.M., Srinivasan, P., Dodson, K.M., \& Sismanis, A. (2009). Receptive language outcomes in children after cochlear implantation. Otolaryngology-Head and Neck Surgery, 140, 114-119.

Barker, D.H., Quittner, A.L., Fink, N.E., Eisenberg, L.S., Tobey, E.A., Niparko, J.K., \& CDaCI Investigative Team. (2009). Predicting behaviors problems in deaf and hearing children: The influences of language, attention, and parent-child communication. Development and Psychopathology, 21, 373-392.

Baumwell, L., Tamis-LeMonda, C., \& Bornstein, M. (1997). Maternal verbal sensitivity and child language comprehension. Infant Behavior and Development, 20, $247-$ 258.

Bayley, N. (1993). Bayley Scales of Infant Development-Second Edition. San Antonio, TX: The Psychological Corporation.

Bloom, L. (1998). Language acquisition in its developmental context. In w. Damon, D. Kuhn, \& R. Siegler (Eds), Handbook of Child Psychology, 2, (pp. 309-370).

Bornstein, M. (2000). Infant into conversant: Language and non-language processes in developing early communication. In N. Budwig, I.C. Uzgiris, J.V. Wersch, \&V. James (Eds.), Communication: An arena of development (pp. 109-129). Westport, CT: Ablex Publishing. 
Bornstein, M., Haynes, O., \& Painter, L. (1998). Sources of child vocabulary competence: A multivariate model. Journal of Child Language, 25(2), 367 -393.

Catts, H., Fey, M., Tomblin, J., \& Zhang, X. (2002). A longitudinal investigation of reading outcomes in children with language impairments. Journal of Speech, Language, and Hearing Research, 45, 1142-1157.

Chapman, R.S. (2000). Children's language learning: An interactionist perspective. Journal of Child Psychology and Psychiatry: Annual Research Reviews, 41, 3354.

Cohen, N.L., Waltzman, S.B., Roland, J.T.J, Staller, S.J., \& Hoffman, R.A. (1999). Early results using the Nucleus CI24M in children. American Journal of Otology, 20, 98-204.

Cook, R., Tessier, A., Klein, M., \& Armbruster, V. (2000). Nurturing communication skills. In R.E. Cook, A. Tessier, \& M.D. Klein (Eds.), Adapting early childhood curricula for children in inclusive settings ( $5^{\text {th }}$ ed., pp. 290-339). Englewood Cliffs, NJ: Merrill.

Davis, A., Bamford, J., Wilson, I., Ramkalawan, T. Forshaw, M., \& Wright, S. (1997). A critical review of the role of neonatal hearing screening in the detection of congenital hearing impairment. Health Technology Assessment, 1, 1-176.

Deckner, D.F., Adamson, L.B., \& Bakerman, R. (2003). Rhythm in mother-infant interactions. Infancy, 4, 201-217.

DesJardin, J.L. (2003a). Parenting Stress in Children with Cochlear Implants and Hearing Aids. Unpublished manuscript. 
DesJardin, J.L. (2003b). Coding Transcriptions of Mother-Child Interactions.

Unpublished manuscript, House Ear Institute, Children's Auditory Research and Evaluation Center, California.

DesJardin, J.L. (2009). Empowering families of young children with cochlear implants: Implications for Early Intervention and Language Development. In L.S. Eisenberg (Ed.), Clinical Management of Children with Cochlear Implants. San Diego, CA: Plural Publishing Inc.

DesJardin, J.L., Ambrose, S.E., \&Eisenberg, L.S. (2009). Literacy skills in children with cochlear implants: The importance of early oral language and joint storybook reading. Journal of Deaf Studies and Deaf Education, 14(1), 22-43.

DesJardin, J.L., \& Eisenberg, L.S. (2007). Maternal contributions: Supporting language development in young children with cochlear implants. Ear \& Hearing, 28, 456469.

Dettman, S.J., Pinder, D., Briggs, R.J., Dowell, R.C., \& Leigh, J.R. (2007). Communication development in children who receive the cochlear implant younger than 12 months: risks versus benefits. Ear \& Hearing, 28(suppl), 11S$18 \mathrm{~S}$.

Dettman, S.J., Tomov, A.M., Dowell, R.C., Barker, E.J., Williams, S.S., Hughes, K.C., \& Saldic, I. (2003). Early language outcomes for children with multiple disabilities. Proceedings of the $9^{\text {th }}$ Symposium on Cochlear Implants in Children, Washington, DC. April. 
Dowell, R.C., Dettman, S.J., Blamey, P.J., Barker, E.J., \& Clark, G.M. (2002). Speech perception in children using cochlear implants: prediction of long-term outcomes. Cochlear Implants International, 1, 1-18.

Duchesne, L., Sutton, A., \& Bergeron, F. (2009). Language achievement in children who received cochlear implants between 1 and 2 years of age: Group trends and individual patterns. Journal of Deaf Studies and Deaf Education, 14(4), 465-485..

Enders, C. K. (2001). The performance of the full information maximum likelihood estimator in multiple regression models with missing data. Educational and Psychological Measurement, 61, 713-740.

Estabrooks, W. (2007). The Auditory-Verbal approach: A professional point of view. In S. Schwartz (Ed.), Choices in deafness $\left(3^{\text {rd }}\right.$ ed.). Bethesda, MD: Woodbine House.

Fewell, R.R., \& Deutscher, B. (2004). Contributions of early language and maternal facilitation variables to later language and reading abilities. Journal of Early Intervention, 26(2), 132-145.

Fink N.E., Wang N.Y., Quittner A.L., Eisenberg E.S., Tobey E.A., Niparko J.K., \& the CDaCI Investigative Team (2007). Childhood Development after Cochlear Implantation (CDaCI): Design and baseline characteristics. Cochlear Implants International, 8(2), 92-116.

Garber, A.S., \& Nevins, M.E. (2007). The Newly Implanted Infant/Toddler. HOPE Notes Online Library, from http://www.cochlearamericas.com/Support/1837.asp.

Girolametto, L., \& Weitzman, E. (2006). It takes two to talk-The Hanen Program for parents: Early language intervention through caregiver training. In R.J. 
McCauley, \& M.E. Fey (Eds.), Treatment of language disorders in children (pp.77-103). Baltimore: Paul H. Brookes.

Girolametto, L., Weitzman, E., Wiigs, M., \& Pearce, P.S. (1999).The relationship between maternal language measures and language development in toddlers with expressive vocabulary delays. American Journal of Speech-Language Pathology, 8, 64-374.

Gregory, S., \& Hindley, P. (1996). Annotation: Communication strategies for deaf children. Journal of Child Psychology and Psychiatry, 37, 895-905.

Grimley M.E., Barker, D.H., Cruz, I., Quittner, A.L., \& CDaCI Investigator Team. (April 2009). Speech production in deaf children receiving cochlear implants: Does maternal sensitivity play a role? Poster presented at the 2009 Society for Research in Child Development Biennial Meeting, Denver, CO.

Guralnick, M.J. (2005). Early intervention for children with intellectual disabilities: Current knowledge and future prospects. Journal of Applied Research in Intellectual Disabilities, 18, 313-324.

Hart, B., \& Risley, T. (1999). Observing children and families talking. In B. Hart \& T.R. Riley (Eds.), The social world of children learning to talk (pp. 7-29). Baltimore, MD: Paul H. Brookes Publishing Co., Inc.

Hart, B., \& Risley, T.R. (1995). Meaningful difference in the everyday experience of young American children. Baltimore, MD: Paul H. Brookes.

Hoff, E. (2000). Language development. Pacific Grove, CA: Brooks/Cole.

Holt, R.F., \& Svirsky M.A. (2008). An exploratory look at pediatric cochlear implantation: Is earliest always better? Ear \& Hearing, 29, 492-511. 
Horn, D.L., Fagan, M.K., Dillon, C.M., Pisoni, D.B., \& Miyamoto, R.T. (2007). Visualmotor integration skills of prelingually deaf children: implications for pediatric cochlear implantation. Laryngoscope, 117(11), 2017-2025.

Huttenlocher, J., Haight, W., Bryk, A., Seltzer, M., \& Lyons, T. (1991). Early vocabulary growth: Relation to language input and gender. Developmental Psychology, 27, 236-248.

Individuals with Disabilities Education Improvement Act of 2004. (2004). Amendments to the Individual with Disabilities Education Act. Public Law 108-446. Retrieved March 18, 2008, from http://www.copyright.gov/legislation/p1108-446.pdf.

Kaiser, A.P., \& Hancock, T.B. (2003). Teaching parents new skills to support their young children's development. Infants and Young Children, 16, 9-21.

Kaiser, A.P., Hancock, T.B., \& Hester, P.P. (1998). Parents as co-interventionists: Research on applications of naturalistic language teaching procedures. Infants and Young Children, 10, 46-55.

Kirk, K.I., Miyamoto, R.T., Ying, E.A., Perdew, A.E., \& Zuganelis. (2000). Cochlear implantation in young children: Effects of age at implantation and communication mode. Volta Review, 102, 127-144.

Kluwin, T.N., \& Stewart, D.A. (2000). Cochlear implants for younger children: a preliminary description of the parental decision process and outcomes. American Annals of the Deaf, 145 (1), 26-32.

Kluwin, T.N., \& Stinson, M. (1993). Deaf students in local public high schools. Springfield, IL: Charles C. Thomas. 
Koester, L.S., Papousek, H., \& Smith-Gray, S. (2000). Intuitive parenting, communication, and interaction with deaf infants. In P.E. Spencer, C.J. Erting, \& M. Marschark (Eds.), The Deaf Child in the Family and at School: Essays in Honor of Kathryn P. Meadow-Orlans (pp. 55-71). Mahwah, NJ: Lawrence Erlbaum Associates, Publishers.

Laing, G., Law, J., Levin, A.,\& Logan, S. (2002). Evaluation of a structured test and a parent led method for screening for speech and language problems: prospective population based study. BMJ, 325, 1152-1157.

LaSasso C.J., \& Mobley R.T. (1997). National survey of reading instruction for deaf or hard-of-hearing students in the U.S. Volta Review, 99(1), 31-58.

Lederberg, A. \& Everhart, V. (2000). Conversations between deaf children and their hearing mothers: Pragmatic and dialogic characteristics. Journal of Deaf Studies and Deaf Education, 5, 303-322.

Lederberg, A. \& Prezbindowski, A. (2000). Impact of child deafness on mother-toddler interaction: Strengths and weaknesses. In P.E. Spencer, C.J. Erting, \& M. Marschark (Eds.), The deaf child in the family and at school: Essays in honor of Kathryn P. Meadow-Orlans, (pp. 73-92). Mahwah, NJ: Lawerence Erlbaum Associates, Inc.

Lim, S.Y.C., \& Simser, J. (2005). Auditory verbal therapy for children with hearing impairment. Annals of Academy of Medicine Singapore, 34(4), 307-312.

MacWhinney, B. (2000). The CHILDES project: Tools for analyzing talk. Hillsdale, NJ: Erlbaum. 
Marschark, M. (1993). Origins and interactions in the social, cognitive, and language development of deaf children. In M. Marschark, \& M.D. Clark, Psychological Perspectives on Deafness(pp.7-26). Hillsdale, NJ: Lawrence Erlbaum Associates, Inc.

Marschark, M. (2000). Education and development of deaf children-or is it development and education? In P.E. Spencer, C.J. Erting, \& M. Marschark (Eds.), Essays in honor of Kathryn P. Meadow-Orlans: The deaf child in the family and at school (pp. 275-292). Mahwah, NJ: Lawrence Erlbaum Associates, Inc.

Marschark, M., \& Spencer, P.E. (2003). Oxford handbook of deaf studies, language, and education. New York, NY: Oxford University Press.

McArdle, J. J. (1988). Dynamic but structural equation modeling of repeated measures data. In J. R. Nesselroade, \& R. B. Cattell, (Eds.), The Handbook of Multivariate Experimental Psychology (pp. 561-614). New York: Plenum Press.

McArdle, J. J. \& Hamagami, F. (2001). Latent Difference Score Structural Models for Linear Dynamic Analyses with Incomplete Longitudinal Data. In L. Collins \& A. Sayer, (Eds.), New methods for the analysis of change (pp. 137-176). Washington, DC: APA Press.

McArdle, J. J. \& Nesselroade, J. R. (2002).Growth curve analysis in contemporary psychological research. In J. Schinka, W. Velicer (Vol. Eds.), \& I.B. Weiner (Ed.), Handbook of psychology, volume 2: Research Methods in Psychology (pp. 447-482). New York: Wiley. 
Meadow-Orlans, K., \& Spencer, P. (1996). Maternal sensitivity and the visual attentiveness of children who are deaf. Early Development and Parenting, 5(4), 213223.

Mitchell, T. \& Quittner, A.L. (1996). A multimethod study of attention and behavior problems in hearing-impaired children. Journal of Clinical Child Psychology, 25, 83-96.

Murray, A., Johnson, J., \& Peters, J. (1990). Fine-tuning of utterance length to preverbal infants: Effects on later language development. Journal of Child Language, 17, 511-525.

Muthen, L.K., \& Muthen, B.O. (2008). Mplus: The comprehensive modeling program for applied researchers. User's guide (5th ed.). Los Angeles: Muthen \& Muthen.

NICHD Early Child Care Research Network. (1999). Child care and mother-child interactions in the first three years of life. Developmental Psychology, 35, 13991413.

National Institute on Deafness and Other Communication Disorders. (2000).

Communication options for children who are deaf or hard-of-hearing. Bethesda, MD. NIH Pub. No. 00-4393.

Parment, S., Lynm, C., \& Glass, R. (2004). Cochlear Implants. Journal of the American Medical Association, 291(9), 2398.

Paul, P.V. (1998). Literacy and Deafness: The Development of Reading, Writing, and Literate Thought. Boston: Allyn \& Bacon.

Quittner, A.L., Barker, D.H., Cruz, I., Snell, C., Grimley, M.E. \& Botteri, M. (2010). Parenting stress among parents of deaf and hearing children: associations with 
language delays and behavior problems. Parenting: Science and Practice, 10, 136155.

Quittner, A.L., Cruz, I., Barker, D., Botteri, M., Eisenberg, L., Tobey, E., et al. (April 2007). Maternal sensitivity as a predictorofgrowth in language in deaf and hearingpreschoolers. Poster presented at The 11th International Conference on Cochlear Implant, Charlotte, NC.

Quittner, A.L., Glueckauf, R., \& Jackson, D. (1990).Chronicparenting stress, Moderating vs. mediatingeffectsofsocial support. Journal of Personality and Social Psychology, 59, 1266-1278.

Quittner, A.L., Leibach, P.L., \& Marciel, K. (2004). The impact of cochlear implants on young, deaf children: New methods to assess cognitive and behavioral development. Archives of Otolaryngology, Head and Neck Surgery, 130, 547-554.

Quittner, A.L., Smith, L. Osberger, M., Mitchell, T., \& Katz, D. (1994).The impact of audition on the development of visual attention. Psychological Science, 5,347353.

Quittner, A.L., Steck, J.T., \&Rouiller, R.L. (1991). Cochlear implants in children: A study of parental stress and adjustment. The American Journal of Otology, 12(S), 95-104.

Reynell, J.K., \& Gruber, C.P. (1990). Reynell Developmental Language Scales. Los Angeles: Western Psychological Services.

Roid, G. \& Miller, L. (2002). Leiter International Performance Scale-Revised. Wood Dale, IL: Stoelting Co. 
Sandall, S. Hemmeter, M.L., Smith, B.J., \& McLean, M.E. (2005). DEC recommended practices: A comprehensive guide for practical application in early intervention/early childhood special education. Longmont, CO: Sopris West.

Singer, L.T., Song, L., Hill, B.P., \& Jaffe, A.C. (1990). Stress and depression in mothers of failure-to-thrive children. Journal of Pediatric Psychology, 15, 711-720.

Smith, L., Quittner, A.L., Osberger, M., \& Miyamoto, R. (1998). Audition and visual attention: The developmental trajectory in deaf and hearing populations. Developmental Psychology, 34, 840-850.

Spencer, P. (1991). Mother infant communication at twelve and eighteen months. In Interaction and Support: Mothers and deaf infants (Final Report, Grant MCJ110563). Rockville, MD: The Maternal and Child Health Research Program.

Spencer, P. \& Waxman, R. (1995). Joint attention and maternal attention strategies: 9, 12, and 18 months. In Maternal responsiveness and child competency in deaf and hearing children (Final Report, Grant HO23C10077) Washington, DC: U.S. Department of Education.

Sroufe, L., Egeland, B., \& Carlson, E. (1999). One social world: The integrated development of parent-child and peer relationships. In Collins, W.A. \& Laursen, B. (Eds.), Relationships as developmental contexts. The Minnesota symposia on child psychology (pp. 241-261). Mahwah, NJ: Lawrence Erlbaum Associates.

Svirsky, M.A. (2000). Language development in children with profound and prelingualhearing loss, withoutcochlearimplants. Ann Otol Rhinol Laryngol Suppl, $185,99-100$. 
Svirsky, M.A., Robbins, A.M., Kirk, K.I., Pisoni, D.B., \&Miyamoto, R.T. (2000). Language development in profoundly deaf children with cochlear implants. Psychological Science, 11, 153-158.

Swisher, M. (2000). Learning to converse: How deaf mothers support the development of attention and conversational skills in their young deaf children. In P.E. Spencer, C.J. Erting, \& M. Marschark (Eds.), The deaf child in the family and at school: Essays in honor of Kathryn P. Meadow-Orlans (pp. 21-40). Mahwah, NJ: Lawrence Erlbaum Associates, Inc.

Vygotsky, L. (1962). Thought and language. Cambridge, MA: MIT Press.

Walsh, S., Rous, B., \& Lutzer, C. (2000).The federal IDEA natural environments provisions. In S. Sandall \& M. Ostrosky (Eds.), Young Exceptional Children Monograph Series No. 2 (pp. 3-15). Denver, CO: Division for Early Childhood of the Council for Exceptional Children.

Warren, S.F., Bredin-Oja, S.L., Escalante, M.F., Finestack, L.H., Fey, M.E., \& Brady, N.C. (2006).Responsivity education/Prelinguistic milieu teaching. In R.J. McCauley \& M.E. Fey (Eds.), Treatment of language disorders in children (pp. 47-75). Baltimore: Brookes.

Waxman, R.P. \& Spencer, P.E. (1997). What mothers do to support visual attention: Sensitivities to age and hearing status. Journal of Deaf Studies and Deaf Education, 2, 104-114.

Weizman, Z. \& Snow, C. (2001). Lexical input as related to children's vocabulary acquisition: effects of sophisticated exposure and support for meaning. Developmental Psychology, 37, 265-279. 
Wilson, B.S. \& Dorman M.F. (2008). Cochlear implants: current designs and future possibilities. Journal of Rehabilitation Research and Development, 45, 695-730.

Wolf, L.C., Noh, S., Fisman, S.N., \& Speechley, M. (1989). Brief report: Psychological effects of parenting stress on parents of autistic children. Journal of Autism and Developmental Disorders, 19,157-166.

Wood, D. (1991). Communication and cognition: How the communication styles of hearing adults may hinder-rather than help-deaf learners. American Annals of the Deaf, 136(3), 247-251.

Yoder, P.J., McCathren, R.B., Warren, S.F., \& Watson, A.L. (2001). Important distinctions in measuring maternal responses to communication in prelinguistic children with disabilities. Communication Disorders Quarterly, 22(3), 135-147.

Yoder, P.J., \& Warren, S.F. (1998). Maternal responsivity predicts prelinguistic communication intervention that facilitates generalized intentional communication. Journal of Speech, Language, and Hearing Research, 41, $1207-$ 1219. 


\section{APPENDIX A}

\section{House Ear Institute}

Children's Auditory Research and Evaluation (CARE) Center

Coding Transcriptions of Mother-Child Interactions

Jean L. DesJardin, Ph.D.

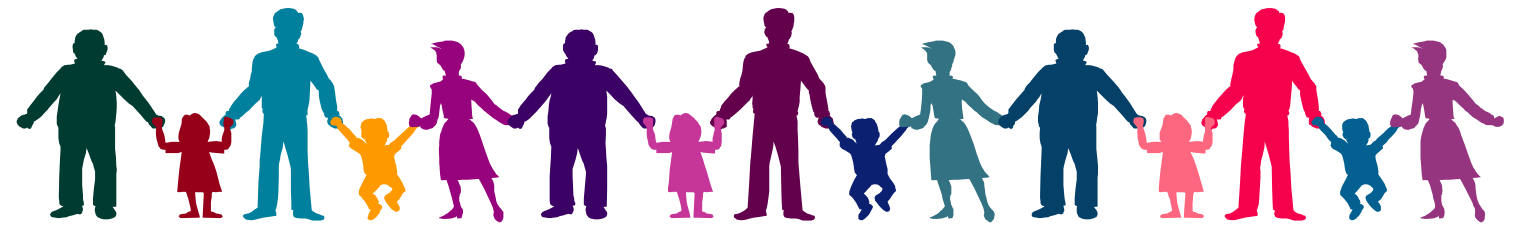


Introduction

Early language intervention for young children with disabilities relies on naturalistic communicative techniques that model aspects of language content, form, and use (Hemmeter \& Kaiser, 1994; McCormick, Loeb, \& Schiefelbusch, 2003; Vukelich, Christie, \& Enz, 2002). In fact, naturalistic communicative techniques constitute in large measure children's language learning lesson. Early interventionists today train parents or a child's primary caretaker to use the following facilitative communicative techniques with their young children in everyday routines in their natural environments (e.g., home, daycare center).

The professional literature targets adult responsiveness to child communication attempts as one of the most important characteristics for facilitating optimal language development in young children with communication delays (Cook, Tessier, Klein, \& Armbruster, 2000; Girolametto, et al., 1999). This model of intervention encompasses a number of different techniques that are derived from social-interactionist accounts of how children learn language from their caregivers' input. Many of the interaction techniques are positively related to later language development in hearing children with expressive language delays (Girolametto, et al., 1999; Nelson, Bonvillian, Denninger, Kaplan, \& Baker, 1984).

Some of the techniques, however, may limit children's word learning. Moreover, some of the techniques have been found to develop language in children with various disabilities that may not be appropriate for children with cochlear implants (e.g., mental retardation and autism). Thus, investigating mothers' communicative techniques and 
children's language learning during natural interaction sessions will further advance our understanding of which communicative techniques better support children's language development in young children with cochlear implants.

For this project, each of the mothers' utterances from the transcriptions is coded for one of the following communicative techniques. Although an utterance may seem to be coded for more than one technique (e.g., label and parallel talk), for this study, the technique that best exemplifies the utterance will be used.

\section{$\underline{\text { Communicative Techniques }}$}

1. Linguistic mapping - LM

2. Continuant or Comment - $\mathrm{CO}$

3. Imitation - IM

4. Label - LB

5. Directive - DR

6. Closed-ended question - CQ

7. Open-ended question or phrase - OQ

8. Expansion - EX

9. Expatiation - EXP

10. Recast - RE

11. Parallel Talk - PT 


\section{$\underline{\text { Facilitative Communicative Techniques }}$}

1. Linguistic mapping(LM) - Putting into words what the child may be trying to communicate without any spoken utterance or providing linguistic input to the child when the child's utterance is unintelligible. For instance, a mother may say what she thinks the child may be trying to convey. To code a mother's utterance for this technique, a child's unintelligible utterance (XXX) must precede it.

\section{Examples from transcriptions}

*CHI: XXX.

*MOT: yes, that's a doggy!

*CHI: XXX.

*MOT: I see the frog.

*CHI: XXX.

*MOT: I need help.

*CHI: XXX.

*MOT: go gogo truck.

2. Continuant or Comment(CO) - statement or phrase that signals that a message has been received and acknowledged. Also, a continuant may be used to keep the conversation going. These signals usually consist of head nods or verbalizations, such as "uh uh" or "okay".

\section{Examples from the transcriptions}

Finished

Yeah!

That's right!

It's okay

I don't know what it is

Let me get my glasses

One more book

You got it! thank you

Oh good job!

uh oh!

oh no!

wait a minute

child's name

oh wow!

You are the best!
I love you!

You're so silly!

Have to turn my phone off way to go!

maybe

oh my goodness

Let's see...

Oops. 
3. Imitation (IM) - mother repeats the child's utterance in whole or in part but makes no evaluative remarks. Mother repeats child's utterance precisely (or fairly closely). Imitations might be preceded by phrases such as "that's right" or "hmm".

Examples from the transcriptions

*CHI: uh oh.

*MOT: uh oh.

*CHI: where frog go?

*MOT: where did frog go?

*CHI: time clean up.

*MOT: hmm time to clean up.

${ }^{*} \mathrm{CHI}:$ I do it!

*MOT: You did it!

4. Label (LB) - Mother labels an object, toy, or picture in the storybook. Child is not necessarily looking at the object or picture.

Examples from the transcriptions

*MOT: That is a bear.

*MOT: Look at the stars.

*MOT: You have an earring.

*MOT: Here is the bowl and cup.

*MOT: This is a spoon.

5. Directive or Command (DR) - Mother tells or directs child to do something.

Examples from the transcriptions

Look! Sit down here $\quad$ Come make a potato

Come here Listen first

Wait

Do this first Stop that!

You play with this cup. 
6. Closed-ended question (CQ) - question or phrase where child can only answer with one word - does not have to follow child's utterance.

Examples from the transcriptions

What color is that?

Do you want a girl?

What's this?

What is the bear holding?

How many frogs are there?

Are you having fun?
What's his name?

Are you finished?

Do you like your Mr. Potato Head?

What is your name?

How old are you?

Do you like that toy?

7. Open-ended question (OQ) - question or phrase where child can answer using more than one word - does not have to follow child's utterance.

\section{Examples from the transcriptions}

Where's the frog going?

What do you think he is saying?

What happened?

Where's he going?

Tell me more about the picture.

What do you think will happen next?

You tell me the story.

What are you making with your cup and spoon?

What will you make with those blocks?

How is the baby feeling?

8.Expansion - Expansions fill in the missing parts in the child's utterances while retaining the child's meaning. The mother expands her child's utterance into a longer utterance, without new information added.

*child utterance must precede this technique

*mother's utterance must contain child's words

Examples from the transcriptions

*CHI: mom girl.

*MOT: that is a girl.

*CHI: green go!

*MOT: green means go! 
9. Expatiation or Extension - Expatiations are similar to expansions, except that new information is added. A mother expands child's utterance into a longer utterance, adding new information.

*child's utterance must precede this technique

*must contain child's word(s) in mother's utterance

Examples from the transcriptions

*CHI: frog.

*MOT: frog and a doggy are hiding.

*CHI: that Krista.

*MOT: she does look like your cousin Krista.

*CHI: bear go!

*MOT: the bear is going to the moon!

*CHI: me done.

*MOT: you are finished playing.

*CHI: stir xx cup.

*MOT: stirring the scrambled eggs in the cup.

10. Recast - Recasts are a specialized form of expansion, involving a change in mood or voice. A mother changes child's utterance into a question statement.

*child's utterance must precede this technique

*child's word(s) must be in mother's utterance

Examples from the transcriptions

*CHI: frog.

*MOT: is frog in the water?

*CHI: red nose.

*MOT: does your Mr. Potato Head have a red nose? 
11. Parallel Talk - provides linguistic labels that describe the mother and/or child's activities or those aspects of the environment to which the mother and/or child is attending. The rationale for engaging in parallel talk is that the child is more likely to acquire those aspects of language that refer to things and actions that he/she finds interesting. Parallel talk usually occurs after a mother and/or child action, rather than a child utterance preceding. Most importantly, the child must be looking directly at either the mother's activity (object/toy) or the child's activity (object/toy).

Examples from the transcriptions

\%act: child picks up the construction hat.

*MOT: you have a yellow hat.

\%act: child puts hat on the potato man.

*MOT: put hat on your potato.

\%act: child looking at specific picture in storybook.

*MOT: he's finding a rocket.

\%act: child looking in container for a toy.

*MOT: looking for eyes for your potato?

\%act: mother picks up a toy and child is looking at the toy.

*MOT: I think this piece goes on top of the house. 